US Army Corps of Engineers ${ }_{\circledast}$ Engineer Research and Development Center

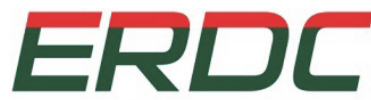

INNOVATIVE SOLUTIONS for a safer, better world

\title{
Spatially-Resolved Characterization
} Techniques to Investigate Impact Damage in Ultra-High Performance Concretes

Robert D. Moser, Paul G. Allison, and Mei Q. Chandler

April 2013

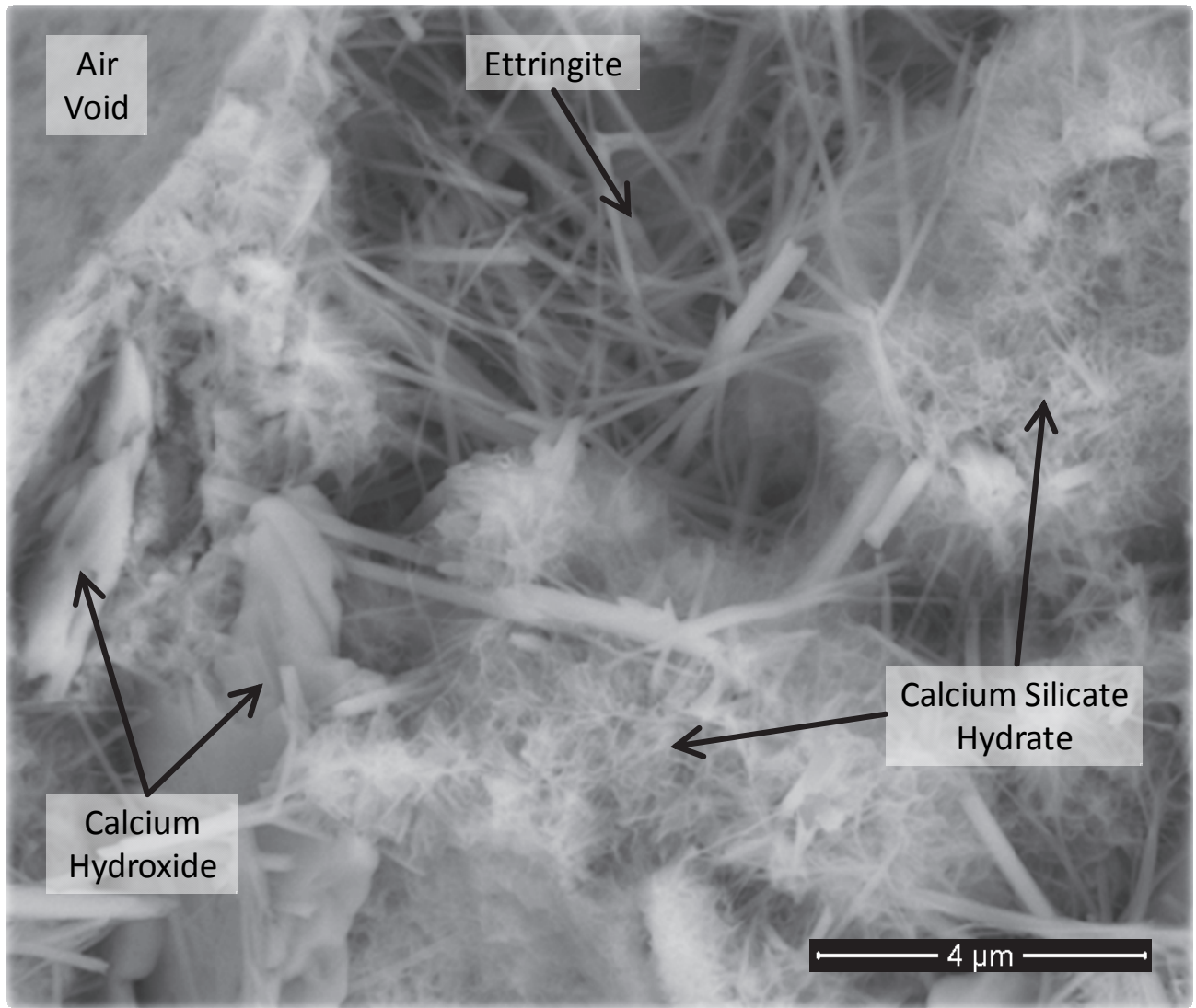


The US Army Engineer Research and Development Center (ERDC) solves the nation's toughest engineering and environmental challenges. ERDC develops innovative solutions in civil and military engineering, geospatial sciences, water resources, and environmental sciences for the Army, the Department of Defense, civilian agencies, and our nation's public good. Find out more at www.erdc.usace.army.mil.

To search for other technical reports published by ERDC, visit the ERDC online library at http://acwc.sdp.sirsi.net/client/default. 


\title{
Spatially-Resolved Characterization Techniques to Investigate Impact Damage in Ultra-High Performance Concretes
}

\author{
Robert D. Moser, Paul G. Allison, and Mei Q. Chandler \\ Geotechnical and Structures Laboratory \\ US Army Engineer Research and Development Center \\ 3909 Halls Ferry Road \\ Vicksburg, MS 39180
}

Final report

Approved for public release; distribution is unlimited.
Prepared for Headquarters, US Army Corps of Engineers
Washington, DC 20314-1000
Under Project Number 149289




\section{Abstract}

Little work has been done to study the fundamental material behaviors and failure mechanisms of cement-based materials including Ordinary Portland Cement concrete (OPC) and Ultra-High Performance Concretes (UHPCs) under high-strain impact and penetration loads at lower length scales. These high-strain rate loadings have many possible effects on UHPCs at the microscale and nanoscale, including alterations in the hydration state and bonding present in phases such as Calcium Silicate Hydrate (C-S-H), in addition to fracture and debonding. In this work, the possible chemical and physical changes in UHPCs subjected to high strain-rate impact and penetration loads were investigated using a novel technique wherein nanoindentation measurements were spatially correlated with images using Scanning Electron Microscopy (SEM) and chemical composition using Energy Dispersive X-ray microanalysis (EDX). Results indicate that impact degrades both the elastic modulus and indentation hardness of UHPCs, and in particular hydrated phases, with damage likely occurring due to microfracturing and debonding.

DISCLAIMER: The contents of this report are not to be used for advertising, publication, or promotional purposes. Citation of trade names does not constitute an official endorsement or approval of the use of such commercial products. All product names and trademarks cited are the property of their respective owners. The findings of this report are not to be construed as an official Department of the Army position unless so designated by other authorized documents. 


\section{Contents}

Abstract........................................................................................................................................ if

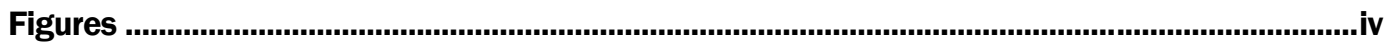

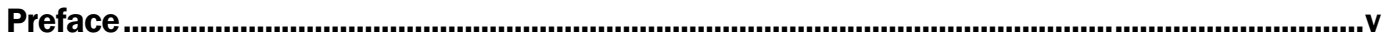

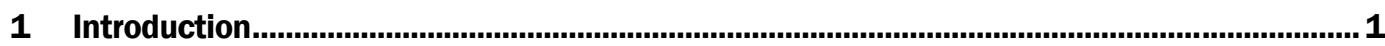

2 Experimental Procedures .................................................................................................. 3

2.1 Materials ......................................................................................................... 3

2.2 Coupled nanoindentation and SEM/EDX analysis ............................................... 3

2.2.1 Specimen preparation .............................................................................................. 3

2.2.2 Nanoindentation .............................................................................................. 5

2.2.3 SEM and EDX measurements ....................................................................... 7

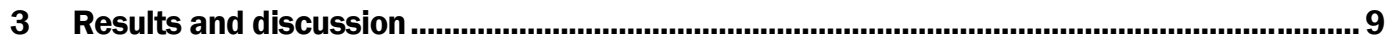

3.1 Overall RPC results ............................................................................................ 9

3.2 Results from hydrated phase fraction .............................................................. 13

4 Conclusions...................................................................................................................17

References...............................................................................................................................................18

Appendix A: Backscattered Scanning Electron Micrographs ....................................................20

Appendix B: Detailed Procedure for Spatially-Correlated Nanoindentation/SEM/EDX

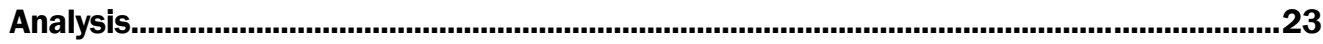

Report Documentation Page 


\section{Figures}

\section{Figures}

Figure. 1. Schematic of experimental setup at ERDC fragmentation simulation facility and location of impacted and non-impacted specimens removed by coring from the UHPC panel 4

Figure 2. Agilent G200 nanoindenter used for nanomechanical testing. ......................................... 6

Figure 3. Schematic of load-displacement curve from nanoindentation with important parameters noted.

Figure 4. FEI Nova NanoSEM 630 scanning electron microscope utilized for microstructural characterization of polished UHPC specimens.

Figure 5. Typical load vs. indentation depth curves for outer and inner hydration products, aggregate, cement, and an aberrant test result.

Figure 6. Typical results from coupled nanoindentation and SEM/EDX studies performed on RPC specimens.

Figure 7. Histogram of elastic modulus results from nanoindentation experiments performed on non-impacted and impacted RPC specimens

Figure 8. Histogram of indentation hardness results from nanoindentation experiments performed on non-impacted and impacted RPC specimens.

Figure 9. Process for down selection of data points corresponding to hydrates from full UHPC data set which includes unhydrated cement, silica fume, fine aggregates, silica flour, and voids.

Figure 10. Hydrated phase fraction elastic modulus of impacted and non-impacted specimens.

Figure 11. Hydrated phase fraction indentation hardness of impacted and non-impacted specimens.

Figure A-1. SEM micrograph of undamaged UHPC specimen.

Figure A-2. SEM micrograph of damaged UHPC specimen, including unhydrated cement, unreacted silica fume, fine aggregates, silica flour, and voids.

Figure A-3. Challenges were encountered during sample preparation.

Figure A-4. Example of well polished UHPC surface for nanoindentation testing and SEM/EDX analyses.

Figure A-5. Typical $2 \mathrm{mN}$ indent on surface of siliceous fine aggregate.

Figure B-1. Plan view of SEM chamber showing proper alignment of specimen "marking" indicator to ensure that coordinate system of images obtained in SEM correspond to that of images observed in the nanoindenter and the statistical nanoindentation grid.

Figure B-2. Proper alignment of specimen in holder for placement in nanoindenter to ensure coordinate system in SEM aligns with that of nanoindenter. 


\section{Preface}

This study was conducted under the Military Engineering Basic Research Program, under Project Number, 149289, "Multiscale Modeling of Structure of Materials," sponsored by Headquarters, US Army Corps of Engineers. The technical monitor was Dr. David A. Horner, Technical Director for Military Engineering, US Army Engineer Research and Development Center (ERDC).

The work was performed by the Concrete and Materials Branch (GM-C) of the Engineering Systems and Materials Division (GM) and Structural Mechanics Branch (GS-M) of the Geosciences and Structures Division (GS), US Army Engineer Research and Development Center - Geotechnical and Structures Laboratory (ERDC-GSL).

The authors would like to thank Dr. Todd Rushing of the Geotechnical and Structures Laboratory, US Army Engineer Research and Development Center (ERDC) for supplying the specimens for this study. Financial support for this work was provided by ERDC and the US Department of Defense SMART Scholarship Program.

At the time of publication, Christopher Moore was Chief, Concrete and Materials Branch; Dr. Will McMahon was Chief, Structural Mechanics Branch; Dr. Larry N. Lynch was Chief, Engineering Systems and Materials Division; Bart P. Durst was Chief, Geosciences and Structures Division; and Dr. David Horner was the Technical Director for Military Engineering. The Deputy Director of GSL was Dr. William P. Grogan, and the Director was Dr. David W. Pittman.

COL Kevin J. Wilson was the Commander of ERDC, and Dr. Jeffery P. Holland was the Director. 


\section{Introduction}

The ubiquitous use of cementitious materials within protective infrastructures makes quantifying their responses to high strain-rate penetration and impact loads a critical need as designs become more reliant on computational tools. Low water-to-cementitious materials ratio $(\mathrm{w} / \mathrm{cm})$ reactive powder concretes (UHPCs) exhibit superior compressive strength (and ductility when fibers are admixed) when compared to conventional concrete, and are being used increasingly for high strain-rate loading applications (Millard et al. 2010). To explore the potential of this material fully for high strain-rate loading applications, its fundamental failure mechanisms under impact and penetration loads need to be investigated. UHPCs are a highly heterogeneous material with a w/ $\mathrm{cm}$ typically less than 0.30 and a microstructure consisting of Hydrated Cement Paste (HCP), unhydrated cement grains, fine aggregates, potentially steel fibers and/or polymer fibers, and pores ranging from nanometers to millimeters in diameter (Rushing et al. 2009). The addition of pozzolanically reactive silica fume results in an HCP comprised primarily of Calcium Silicate Hydrate (C-S-H).

C-S-H is the most important phase of the Portland cement hydration process and functions as the binding component that holds the various other phases of UHPCs together. C-S-H consists of physically and chemically bound water in nanometer-scale gels, bulk water in gel and capillary pores, adsorbed water on the surfaces of gels, and may behave nanogranularly (Constantinides and Ulm 2007). Grady (1996) suggests that C-S-H may go through chemical changes such as dehydration or vaporization under shock impact loading.

Instrumented indentation, namely nanoindentation, techniques have been used to quantify the structure-property relationships of concrete at lower length scales. Velez et al. (2001) performed nanoindentation tests to quantify the elastic modulus and hardness of synthetically manufactured Portland cement clinker phases. Hughes and Trtik (2004) used depthsensing nanoindentation and Energy Dispersive X-ray (EDX) analysis to correlate the major phase compositions and mechanical properties of hydrated cement paste. Ulm et al. (2007) developed a novel statistical nanoindentation technique to characterize cement paste and were able to 
identify the existence of two types of C-S-H, Low-Density (LD) and HighDensity (HD) C-S-H. Constantinides and coworkers (DeJong and Ulm 2007; and Constantinides and Ulm 2004) used a similar approach to study the degrading mechanisms of calcium leaching and high temperature on C-S-H. Sorelli et al. (2008) also used similar techniques to characterize the properties and volume fraction of different phases in UHPCs. Their research showed that UHPCs with a low water-to-cement $(w / \mathrm{cm})(0.2)$ have a much higher volume fraction of HD C-S-H and unhydrated clinker than LD C-S-H compared to concrete with higher $w / c$. More recent efforts by Chen et al. (2010) have investigated the use of spatially correlated nanoindentation/SEM/ EDX techniques similar to those employed herein to investigate the effect of composite formations of C-S-H and $\mathrm{Ca}(\mathrm{OH})_{2}$ on mechanical response measured using nanoindentation (Chen et al. 2010).

In this work, the influence of impact loadings on the nanomechanical properties of UHPCs was investigated. Specimens were extracted from impacted and non-impacted panels of UHPC. A novel technique coupling nanoindentation with spatially correlated Scanning Electron Microscopy (SEM) and chemical analysis using Energy Dispersive X-ray spectroscopy (EDX) was developed to characterize damage due to high strain-rate impact loadings in the UHPC panels. Based on the results of these studies, a possible mechanism for microstructural damage in UHPCs was proposed. Caveats associated with the techniques used are also discussed. 


\section{Experimental Procedures}

\subsection{Materials}

A UHPC mixture (Baseline Cor-Tuf) with a w/cm of 0.2 and an unconfined compressive strength of $180 \mathrm{MPa}$ was cast into panels $305-\mathrm{mm}$ wide by 305-mm long and 25.4-mm thick for ballistic impact testing. The mixture composition included Class $\mathrm{H}$ cement, silica fume, silica flour, siliceous fine aggregate, super plasticizer, and potable tap water. The cast panels underwent a standard high-temperature curing process prior to testing. Following the curing process, the panels were impacted by $11-\mathrm{mm}$-diameter steel spheres at $\mathrm{V}_{50}$, the velocity at which there is a 50 percent probability of the sphere fully penetrating the panel. The experiments were conducted at the ERDC fragmentation simulation facility (Figure 1a), V50 values were determined according to MIL-STD-662 (1997).

\subsection{Coupled nanoindentation and SEM/EDX analysis}

Analyses of impacted and non-impacted UHPC specimens were performed using a novel technique of nanoindentation coupled with SEM imaging and EDX chemical analysis. In this coupled method, a large number of indents are performed over a standardized indentation grid placed on the UHPC specimen, after which each indent is spatially correlated using SEM to obtain an image and EDX to determine the chemical composition. The resulting data set contains the nanomechanical properties and chemical composition along with an image at each indentation site. This method allows for improved differentiation between the various components present in UHPCs and can be used to better correlate alterations in nanomechanical properties (e.g., due to impact loadings) to specific microstructural features. Details on specimen preparation techniques and experimental methods are described below.

\subsubsection{Specimen preparation}

Specimens were extracted from the UHPC panel in the impacted zone and a non-impacted zone, as shown in Figure $1 \mathrm{~b}$. The center of the non-impacted location was $38 \mathrm{~mm}$ from both the top edge and side of the panel. This location was selected to minimize the potential for edge effects from casting, while also avoiding the damaged zone to the greatest extent. 


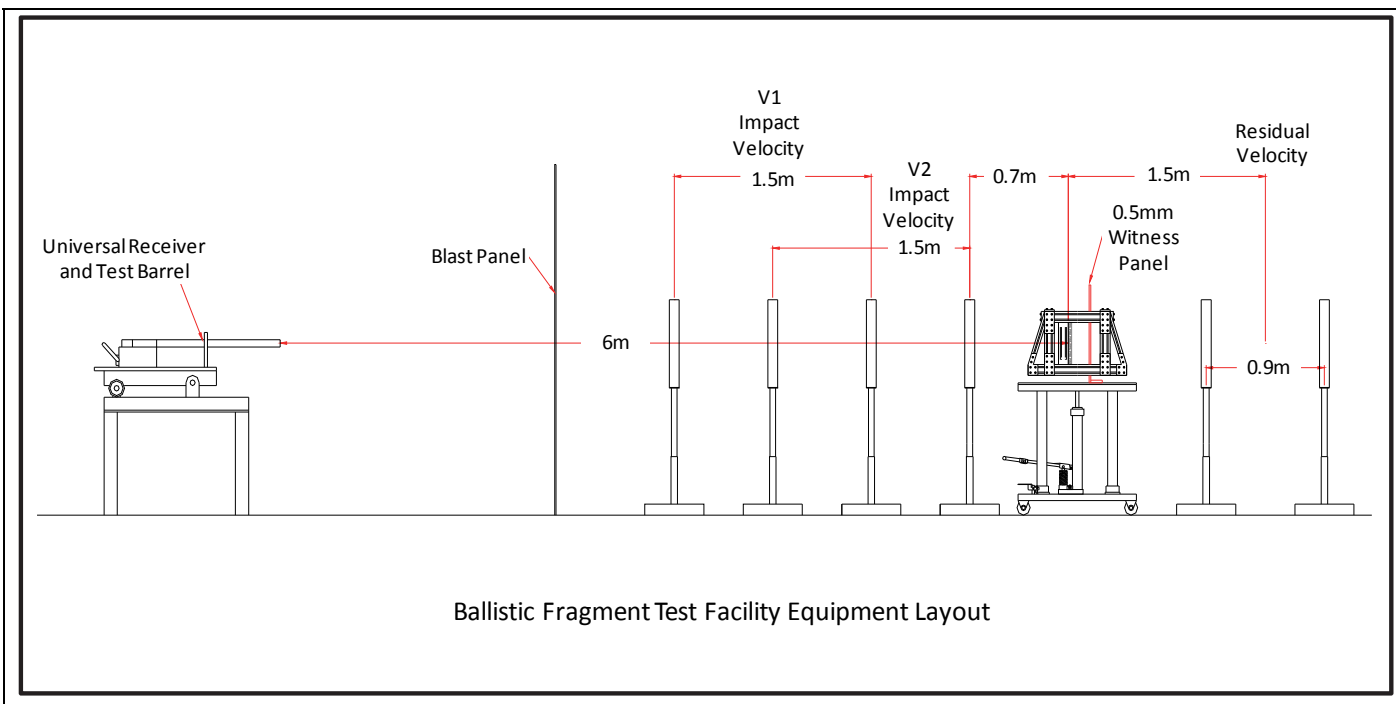

(a) Schematic of ERDC fragmentation simulation facility use for testing.

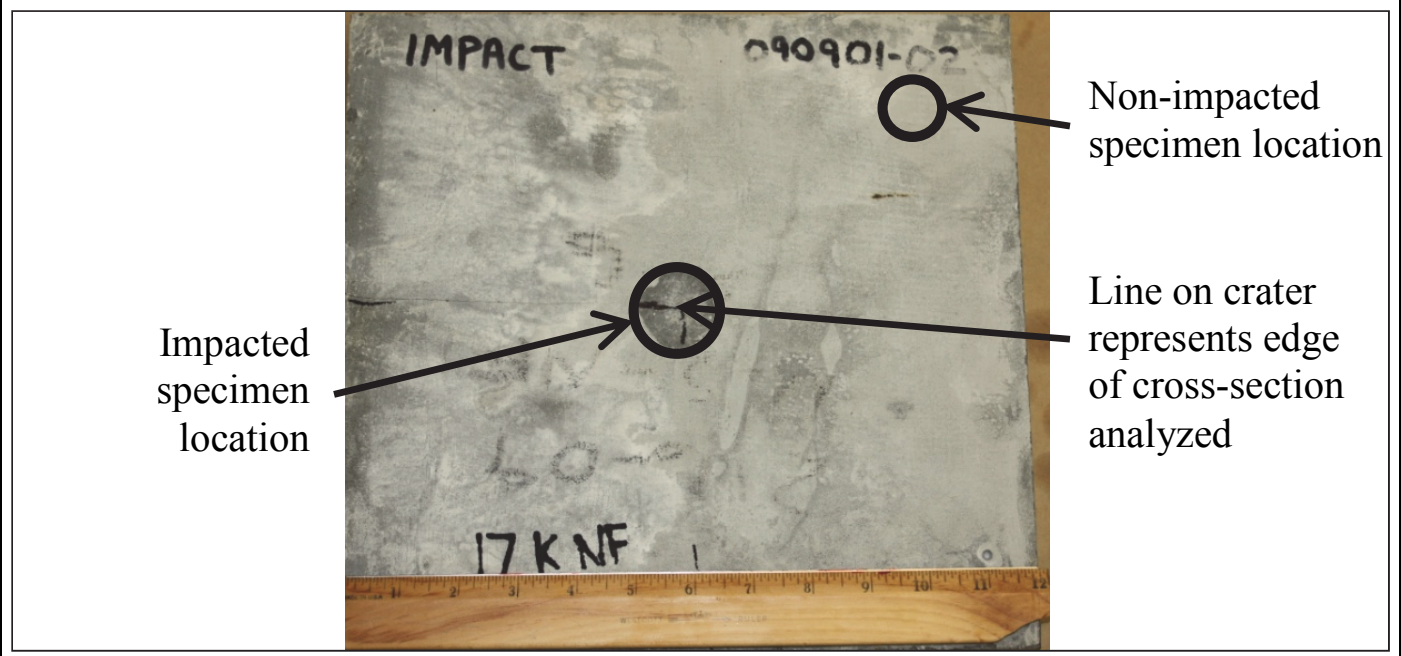

(b) Typical UHPC panel following testing.

Figure. 1. Schematic of experimental setup at ERDC fragmentation simulation facility and location of impacted and non-impacted specimens removed by coring from the UHPC panel.

A 25.4-mm-diameter diamond-tipped coring bit was used to core the nonimpacted specimens, which were then cast into 31.8-mm-diameter cylindrical molds using EpoHeat low-viscosity epoxy, supplied by Buehler. The impacted specimen was sectioned using an oil-cooled Struers Secotom high-precision cut-off saw. The cross-section of the specimen was placed into a 31.8-mm-diameter cylindrical mold and mounted in EpoHeat epoxy, from Buehler. After the epoxy cured fully, the samples were sectioned in half by the oil-cooled cut-off saw to obtain a cross-section from the center of the panel, thus limiting any surface effects such as laitance. 
A Buehler Ecomet/Automet 250 automatic polishing wheel was used to polish the extracted specimens. The polishing procedure utilized a 240-grit diamond polishing pad at $230 \mathrm{rpm}$ until the specimen was planar, followed by an UltraPad ${ }^{\mathrm{TM}}$ with a $9-\mu \mathrm{m}$ diamond paste at $130 \mathrm{rpm}$ for 5 -min, a TriDent ${ }^{\mathrm{TM}}$ pad with a $3-\mu \mathrm{m}$ diamond paste for 5 -min and with a $0.3-\mu \mathrm{m}$ diamond paste for 5 -min, and finally a ChemoMet ${ }^{\circledR}$ pad with $50-\mathrm{nm}$ colloidal silica for 5-min. These polishing steps used a 50:50 mixture of ethylene glycol $\left(\mathrm{C}_{2} \mathrm{H}_{6} \mathrm{O}_{2}\right)$ and ethanol $\left(\mathrm{C}_{2} \mathrm{H}_{6} \mathrm{O}\right)$ for a polishing lubricant. All steps used a force of $30 \mathrm{~N}$ per specimen for polishing. Once polished, the specimens were stored in a vacuum dessicator prior to testing.

\subsubsection{Nanoindentation}

Polished specimens were examined using an Agilent Technologies G200 nanoindenter (Figure 2) to probe microstructural changes across the surface of impacted and non-impacted regions. Indentation testing was performed using a pyramid-shaped diamond Berkovich indenter with a tip radius of approximately $20 \mathrm{~nm}$. Prior to each measurement, a second-order area function calibration was performed using a fused silica reference material. Load-controlled indentation measurements were performed up to a maximum load of 2-mN at a loading rate of $0.2 \mathrm{mN} / \mathrm{sec}$ followed by a hold time of 5-sec and a 10-sec unloading period. A hold segment in air corrected for thermal drift by waiting until the thermal drift was less than $0.5 \mathrm{~nm}-\mathrm{sec}^{-1}$ before testing commenced.

Prior to performing the nanoindentation experiments, each specimen was examined in the SEM to create a "map" of images approximately 3-mm by 3-mm near the indentation site. This "map" was then used to find a desired location for the indentation grid (i.e., not containing large voids and/or surface defects).

For each specimen, a total of 500 indents were placed with a spacing of $10-\mu \mathrm{m}$ in the $\mathrm{X}$-direction and $20-\mu \mathrm{m}$ in the Y-direction. Following the indents performed for nanomechanical measurements, $100-\mathrm{mN}$ fiduciary indents were placed at a spacing of $245-\mu \mathrm{m}$ in the X-direction and $20-\mu \mathrm{m}$ in the Y-direction from the first indent to aid in identifying the start, middle, and end of each line of indents, so that the indents could be located precisely using the SEM/EDX technique. Assuming a Poisson's ratio of 0.2, mechanical properties such as elastic modulus and indentation hardness were determined for the interaction region of each indentation site. 


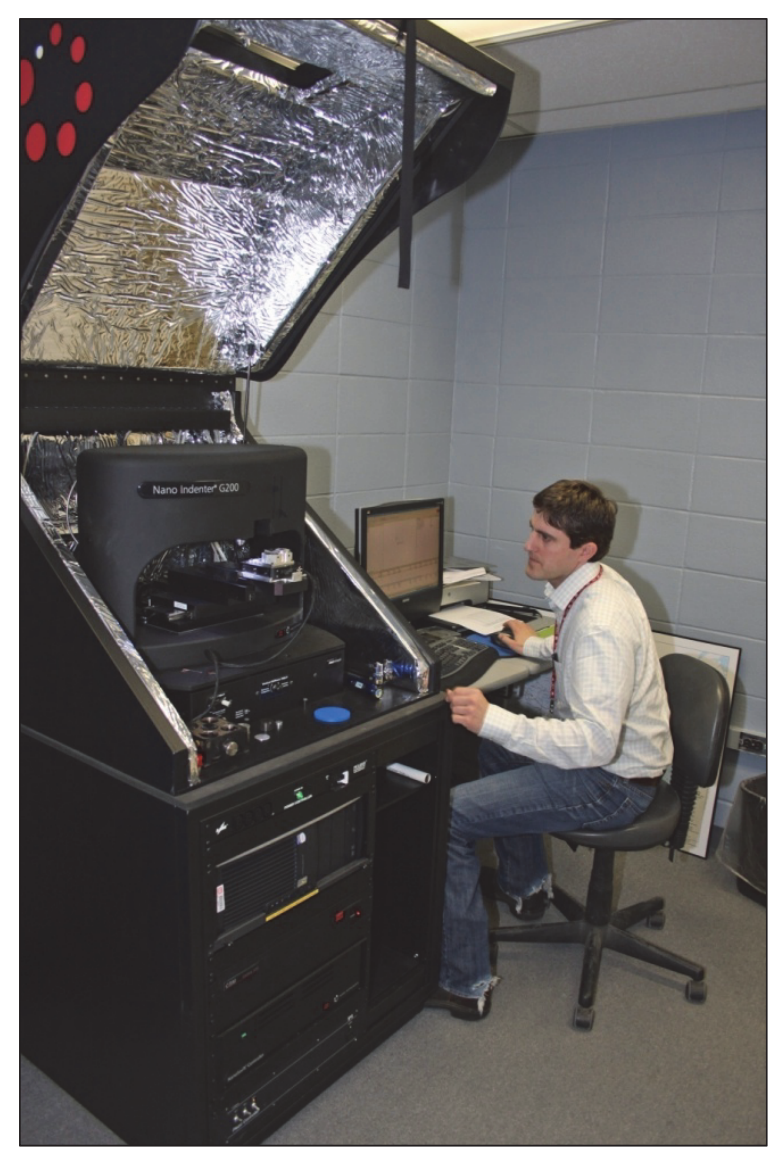

Figure 2. Agilent G200 nanoindenter used for nanomechanical testing.

The Oliver and Pharr (1992) method was used to calculate elastic modulus and indentation hardness at each indent. This method uses the initial unloading portion of the load-displacement curve (Figure 3) to determine contact stiffness. The hardness, $H$, and contact stiffness, $S$, expressions used are:

$$
\begin{gathered}
H=\frac{P \max }{A} \\
S=\beta \frac{2}{\sqrt{\pi}} E_{f} \sqrt{A}
\end{gathered}
$$

where $P_{\max }$ is the maximum load during indentation, $A$ is the contact area, $\beta$ is a dimensionless correction factor $(\beta=1.034$ for Berkovich indenter tips), and the effective elastic modulus, $E_{f}$, incorporates the elastic displacement occurring for both the specimen and the indenter as: 


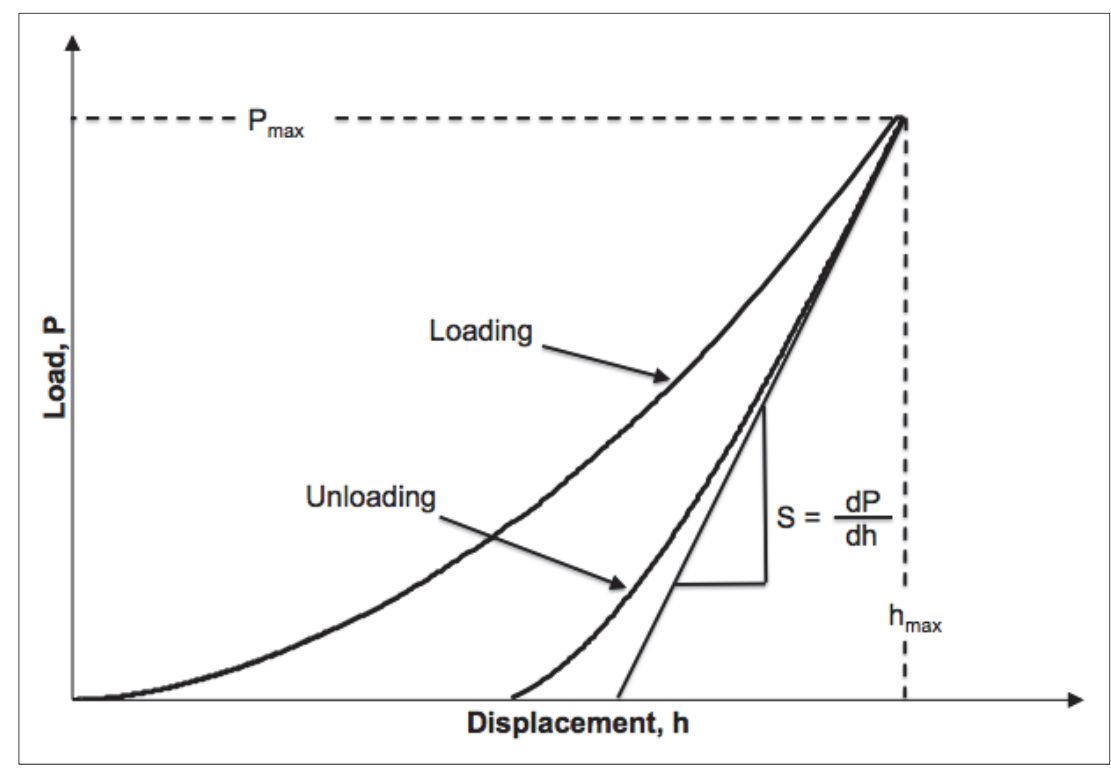

Figure 3. Schematic of load-displacement curve from nanoindentation with important parameters noted.

$$
\frac{1}{E_{f}}=\frac{1-v^{2}}{E}+\frac{1-v_{i}^{2}}{E_{i}}
$$

where the elastic modulus, $E$, and Poisson's ratio, $v$, are for the specimen surface of interest, and $E_{i}$ and $v_{\mathrm{i}}$ are the elastic modulus and Poisson's ratio of the indenter, respectively.

\subsubsection{SEM and EDX measurements}

Specimens were examined before and after nanoindentation using an FEI Nova NanoSEM 630 variable pressure field emission SEM (Figure 4). Imaging was performed at an accelerating voltage of $10-\mathrm{kV}$ using a backscattered electron (BSE) detector to reveal changes in microstructure and the distribution of phases according to their respective densities. When examined after nanoindentation, the "map" of images was used to generally locate the indentation grid, while the fiduciary indents were used to determine the location of each line of indents, such that each indent could be correlated with a location on the image. Point chemical analyses were also performed in conjunction with SEM imaging using a Bruker solid-state EDX detector installed in the FEI SEM. Through proper alignment of the indentation grid facilitated by the fiduciary indents, a standardized point chemical analysis grid was developed that resulted in a data set of point chemical analyses that were spatially correlated with the location of each indent. 


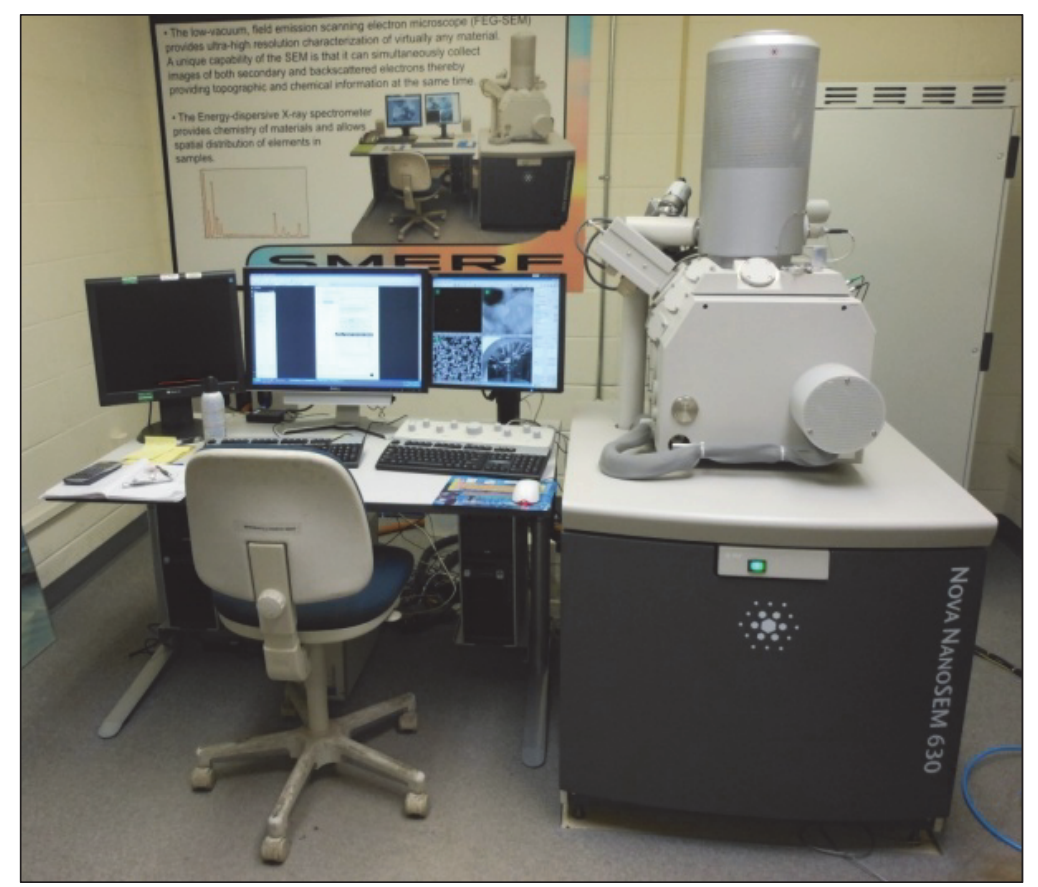

Figure 4. FEI Nova NanoSEM 630 scanning electron microscope utilized for microstructural characterization of polished UHPC specimens. 


\section{Results and Discussion}

\subsection{Overall RPC results}

The highly variable phase composition and distribution present in UHPCs present a variety of different nanomechanical properties that were sampled during nanoindentation measurements. Figure 5 shows the load vs. depth results of five representative indents corresponding to a fine aggregate, an anhydrous cement grain, hydration products, and an aberrant test. Hydration products were divided into two phases, namely outer (lowdensity) hydration products at a distance from cement grains and inner (high-density) hydration products in closer proximity to cement grains, which were determined through molecular simulations and similar nanoindentation studies (Constantinides and Ulm 2004). Of particular interest is the faulty or "aberrant" test result shown in Figure 5, which defies the traditional stiffening indentation curve typical for homogenous interaction regions, but still exhibits an elastic modulus similar to a homogenous phase (in this case inner hydration products).

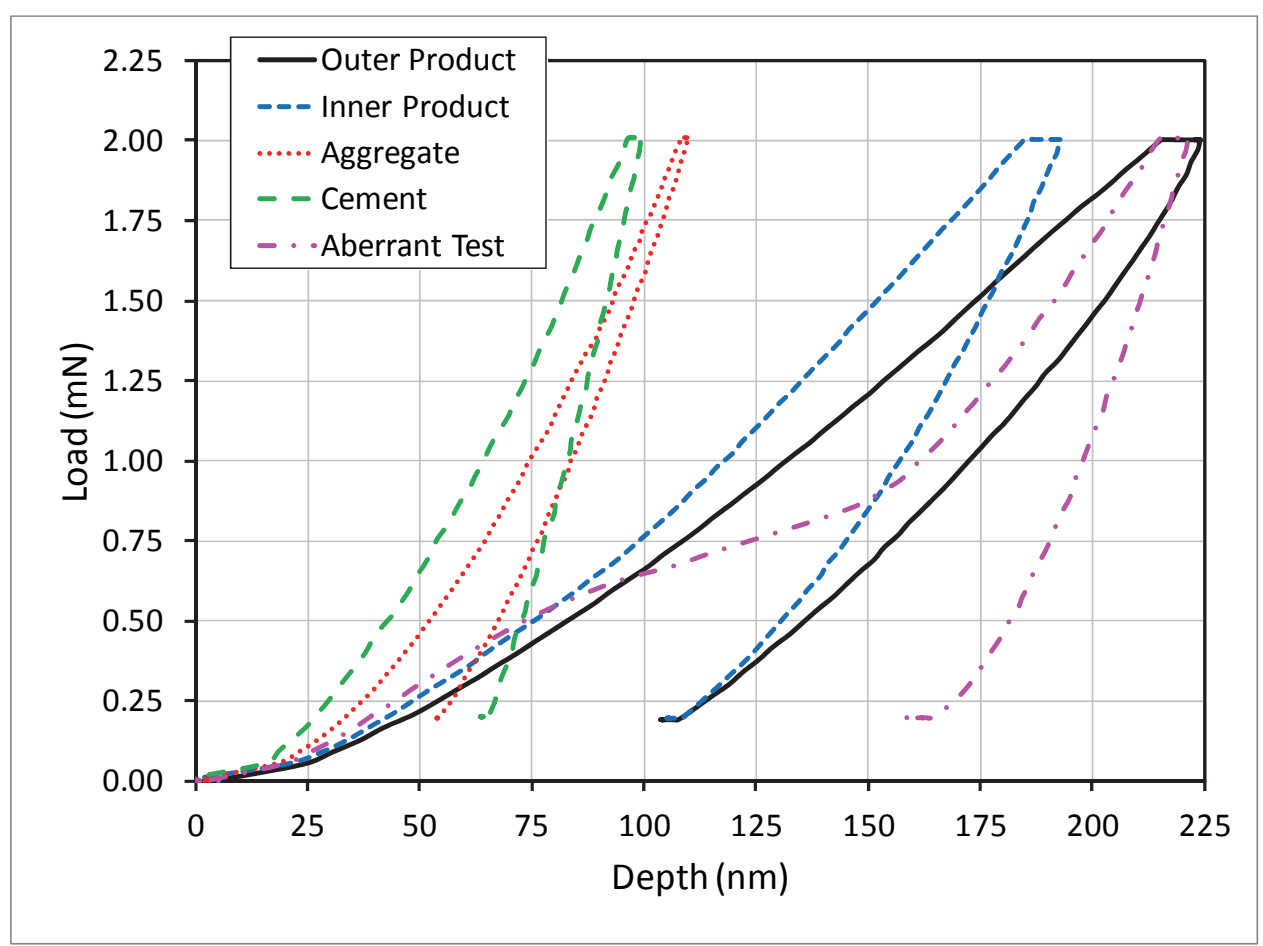

Figure 5. Typical load vs. indentation depth curves for outer and inner hydration products, aggregate, cement, and an aberrant test result. 
These aberrant tests may present themselves as irregular loading and/or unloading curves (as shown in Figure 5). In heterogeneous cement-based materials, aberrant test results may occur due to the presence of voids, polishing defects, cracking during indentation, and as noted more recently, composite or "nanocomposite" multiphase response of material present in the interaction region of the indent (Chen et al. 2010; Davydov et al. 2011; and Trtik et al. 2009). The multiphase response of cementbased materials is a topic of recent discussion in the literature and represents an issue that may diminish the utility of nanoindentation as a quantitative microstructural characterization technique. Thus, it is critical to examine each indentation curve and remove aberrant results if reliable quantitative information is desired. All indentation curves in the present study were reviewed, and eight percent in impacted specimens and 24 percent in non-impacted specimens were deemed aberrant and removed from the data set.

Figure 6a illustrates a typical grid of 500 measurement indentation points and fiduciary indents superimposed on a BSE micrograph of an UHPC specimen. Using BSE imaging, the anhydrous cement and silica fume can be seen with a bright signature, followed by fine aggregates and silica flour, and finally by the HCP (i.e., solid products of cement hydration with low density) and voids that appear darkest in the image. The HCP appeared to be comprised primarily of C-S-H, with all $\mathrm{Ca}(\mathrm{OH})_{2}$ likely consumed by pozzolanic reactions and subsequently converted into supplementary $\mathrm{C}-\mathrm{S}-\mathrm{H}$. Figures $6 \mathrm{~b}$ and $6 \mathrm{c}$ present contour maps of $\mathrm{Ca}$ :Si ratio and elastic modulus results, respectively, corresponding to the indentation grid shown in Figure 6a. A clear correlation can be observed between the location of the various components of the UHPC and their respective chemical composition and mechanical properties.

The benefits of using this coupled nanoindentation/SEM/EDX technique are particularly apparent when trying to differentiate between phases with similar properties. For example, fine aggregate particles and anhydrous cement present in low w/c concretes may exhibit similar mechanical properties, which make phase identification/quantification from only nanoindentation results a challenging task. However, when nanoindentation measurements are coupled with chemical composition at the indentation site, the distinction between fine aggregates (with low $\mathrm{Ca}: \mathrm{Si}$ approaching zero) and cement (with high $\mathrm{Ca}: \mathrm{Si}$ of 5 to 7) becomes clear. Similar comparisons can be made for the various phases of cement hydration present in the HCP. 


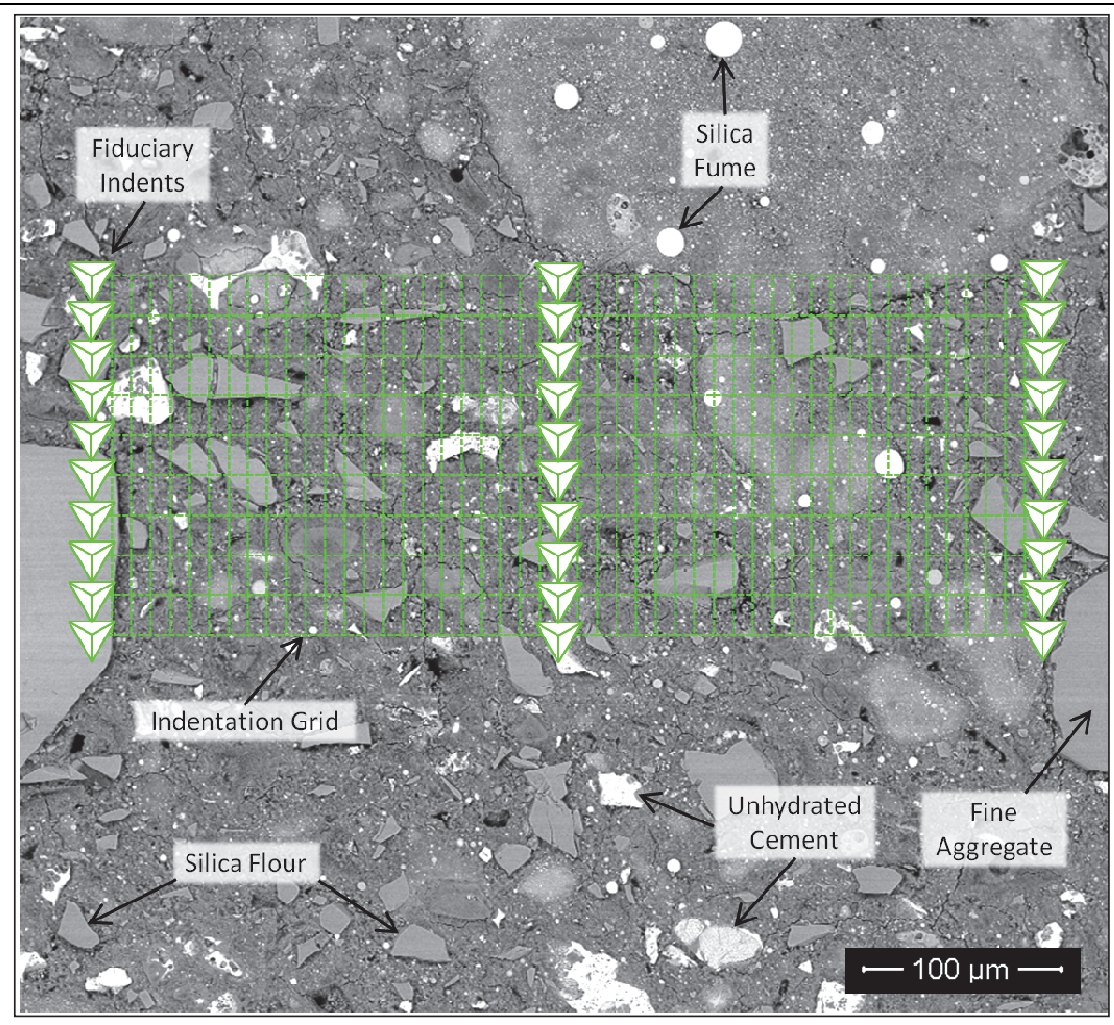

a) SEM-BSE micrograph of typical reactive powder concrete microstructure with measurement indentation grid and fiduciary indents superimposed.

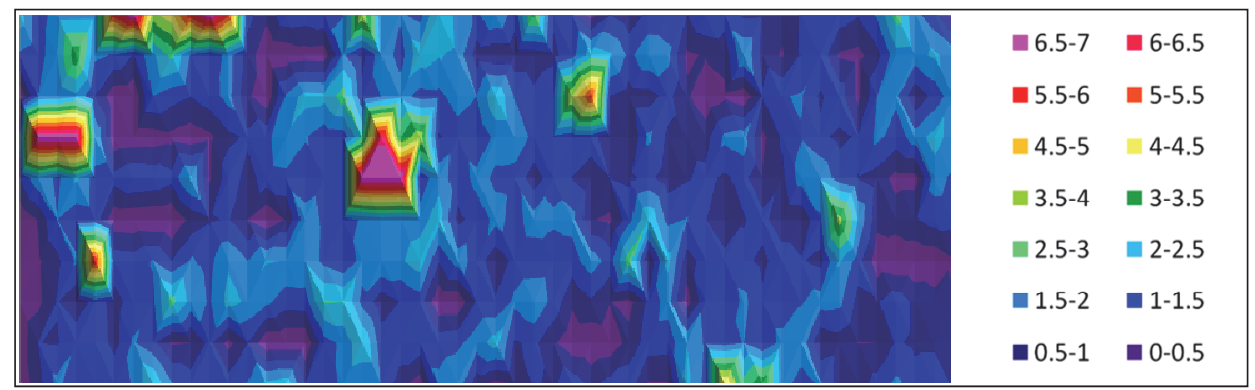

b) Map of Ca:Si corresponding to indentation grid.

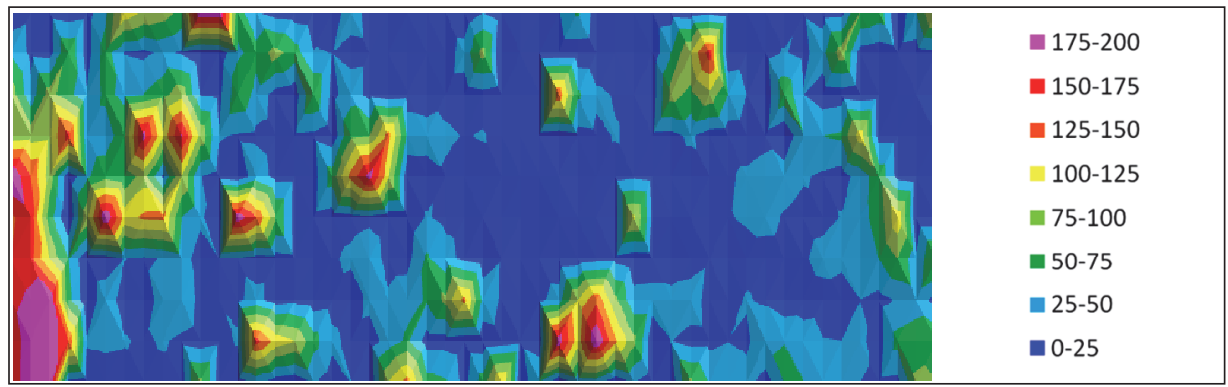

c) Map of elastic modulus (GPa) corresponding to indentation grid.

Figure 6. Typical results from coupled nanoindentation and SEM/EDX studies performed on RPC specimens. 
Another feature of the nanoindentation measurements clearly shown in the elastic modulus contour map in Figure $6 \mathrm{c}$ is the gradual transition in nanomechanical properties present at interfaces between two phases. This behavior is the result of a composite response of material present within the interaction region below each indent as discussed above.

With the aberrant results removed from the data set, further analyses of "valid" nanoindentation results were performed. Figures 7 and 8 present histograms of the elastic modulus and hardness results of all "valid" indents performed on non-impacted and impacted specimens in the present study. Results presented in Figure 7 encompass those of anhydrous cement, siliceous fine aggregates, silica flour, the HCP (primarily composed of C-S-H), and voids/porosity. Impacted specimens exhibited a mean elastic modulus of 47.9 GPa compared with $76.7 \mathrm{GPa}$ in non-impacted specimens. In particular, significant reductions in the proportion of indents with elastic moduli between $60 \mathrm{GPa}$ and $110 \mathrm{GPa}$ were observed in impacted specimens, a range common for silica flour and siliceous fine aggregates (Sorelli et al. 2008).

The effect of impact (Figure 8) was much more pronounced in hardness measurements, where a large shift in hardness from a mean of $6.3 \mathrm{GPa}$ to 2.7 GPa was observed. In impacted specimens, there was a particularly high increase in the proportion of indents with hardness between 0.5 and 1.5 GPa associated with a reduction in the proportion of indents with hardness above 4.0 GPa.

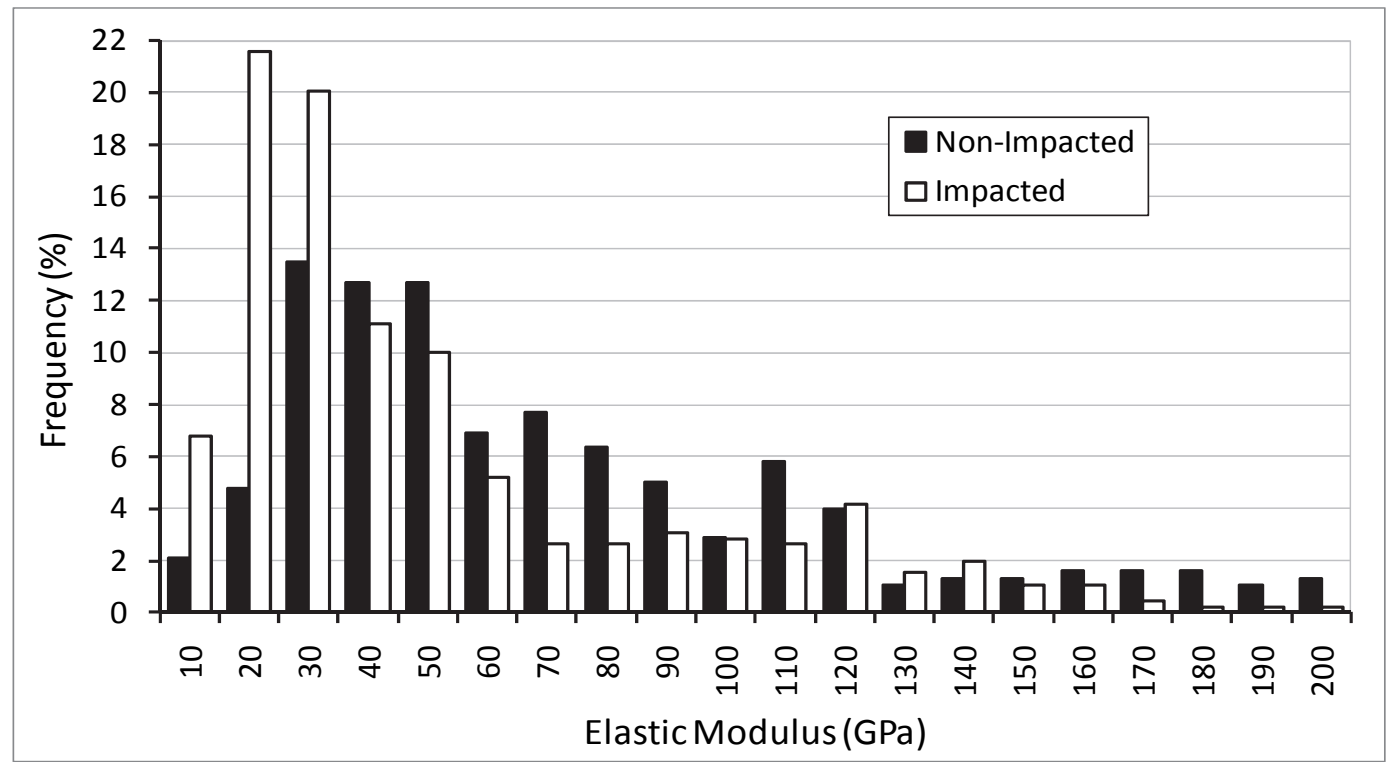

Figure 7. Histogram of elastic modulus results from nanoindentation experiments performed on non-impacted and impacted RPC specimens. 


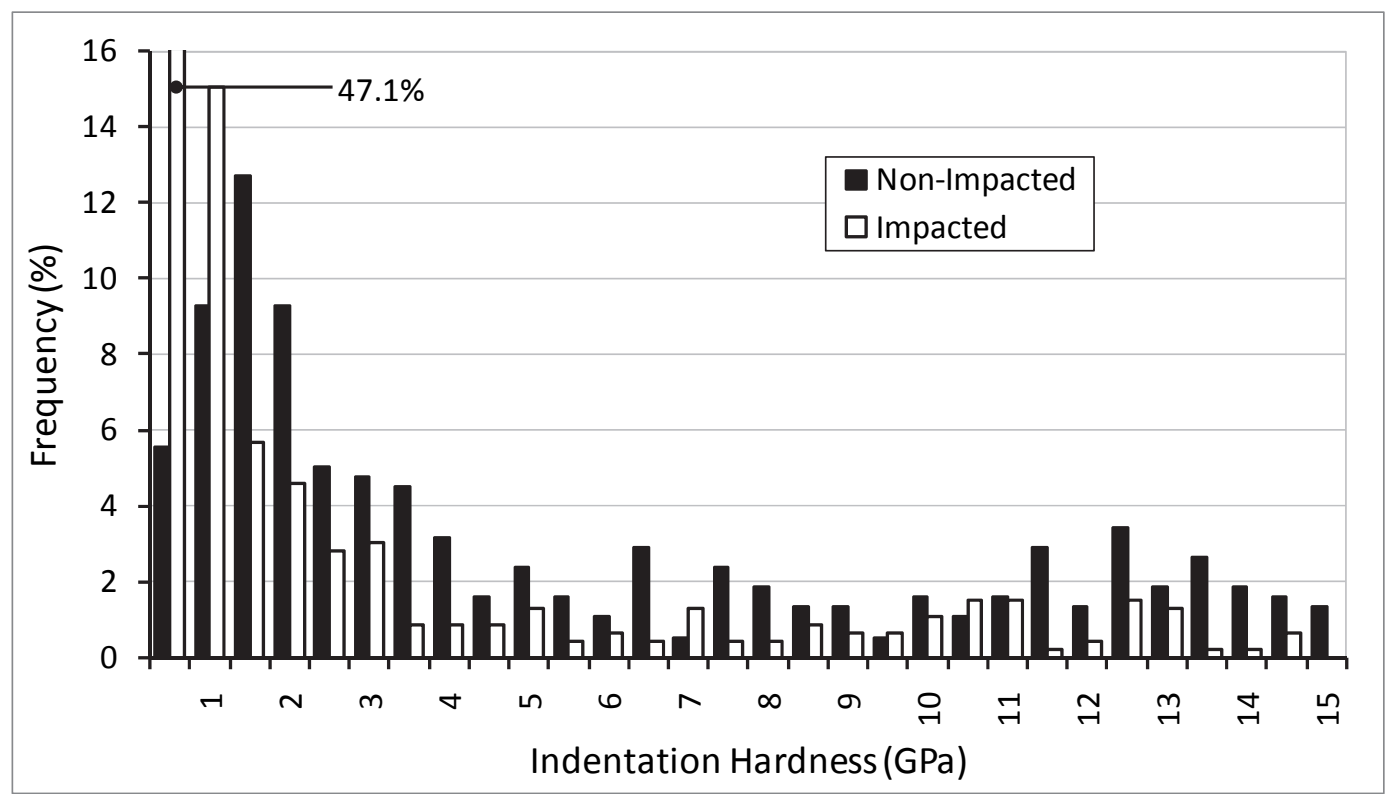

Figure 8. Histogram of indentation hardness results from nanoindentation experiments performed on non-impacted and impacted RPC specimens.

While removal of seemingly aberrant test results did improve the quality of results included in the data set for analysis, measured mechanical properties presented in Figures 7 and 8 indicate values of elastic modulus and hardness that are not theoretically probable (i.e., elastic modulus in excess of $150 \mathrm{MPa}$ ) in typical UHPCs or mortars containing hydrated cement paste and fine aggregates. Such behavior is supported by recent observations of "spurious peaks" that may correspond to surface defects or the presence of multiple hydration products present within interaction volume of the indent (Trtik et al. 2009). This observed behavior in spatially-correlated nanoindentation/SEM/EDX measurements reduces the validity of nanoindentation for determining single-phase nanomechanical properties.

\subsection{Results from hydrated phase fraction}

While these nanoindentation results suggest that impact loadings have a significant influence on the elastic modulus and hardness of UHPCs, it is difficult to determine by what possible mechanism degradation occurs. To further evaluate the possible mechanisms causing the observed degradation in nanomechanical properties, indents likely associated with homogenous regions of hydrated phases were extracted from the full data set of nonimpacted and impacted UHPC specimens (Figure 9). Indents identified as hydrates were selected based on a Ca:Si between 0.5 and 2.0 (consistent with typical C-S-H ) with an elastic modulus between 10 and 50 GPa (range typical for outer and inner product C-S-H (Sorelli et al. 2008; Chen et al. 
2010)). Out of each data set, approximately 10 percent of the indents were deemed as hydrates. Ca:Si ratios of the hydrated phases' sub-data set were 1.44 and 1.42 for non-impacted and impacted specimens, respectively, indicating that the method was successful in identifying regions that contained hydrates of similar chemistry before and after impact.

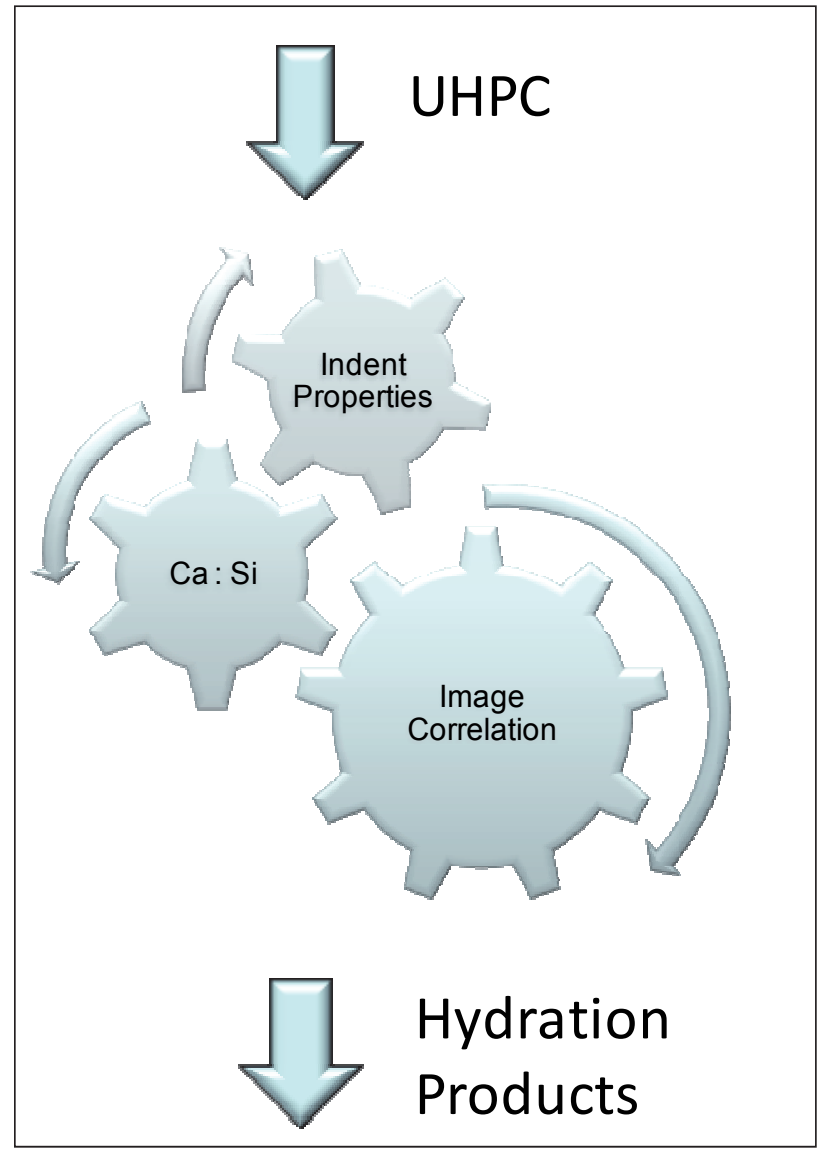

Figure 9. Process for down selection of data points corresponding to hydrates from full UHPC data set which includes unhydrated cement, silica fume, fine aggregates, silica flour, and voids.

The histograms shown in Figures 10 and 11 depict the distribution in elastic modulus and indentation hardness of hydrated phases for non-impacted and impacted specimens. Hydrated phases present in non-impacted specimens exhibited a mean elastic modulus of $32.5 \mathrm{GPa}$ and mean indentation hardness of $1.56 \mathrm{GPa}$. C-S-H present in impacted specimens exhibited a mean elastic modulus of $27.4 \mathrm{GPa}$ and mean indentation hardness of $0.66 \mathrm{GPa}$, with a significant increase in hardness between 0.25 and $0.75 \mathrm{GPa}$. 


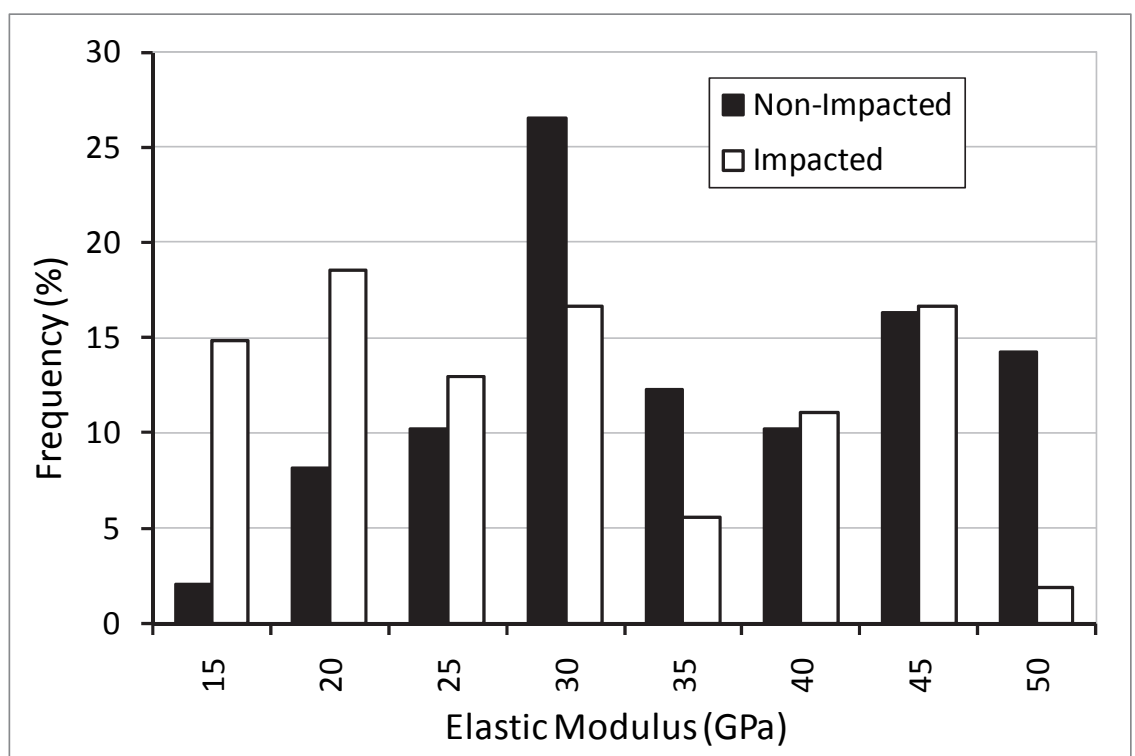

Figure 10. Hydrated phase fraction elastic modulus of impacted and nonimpacted specimens.

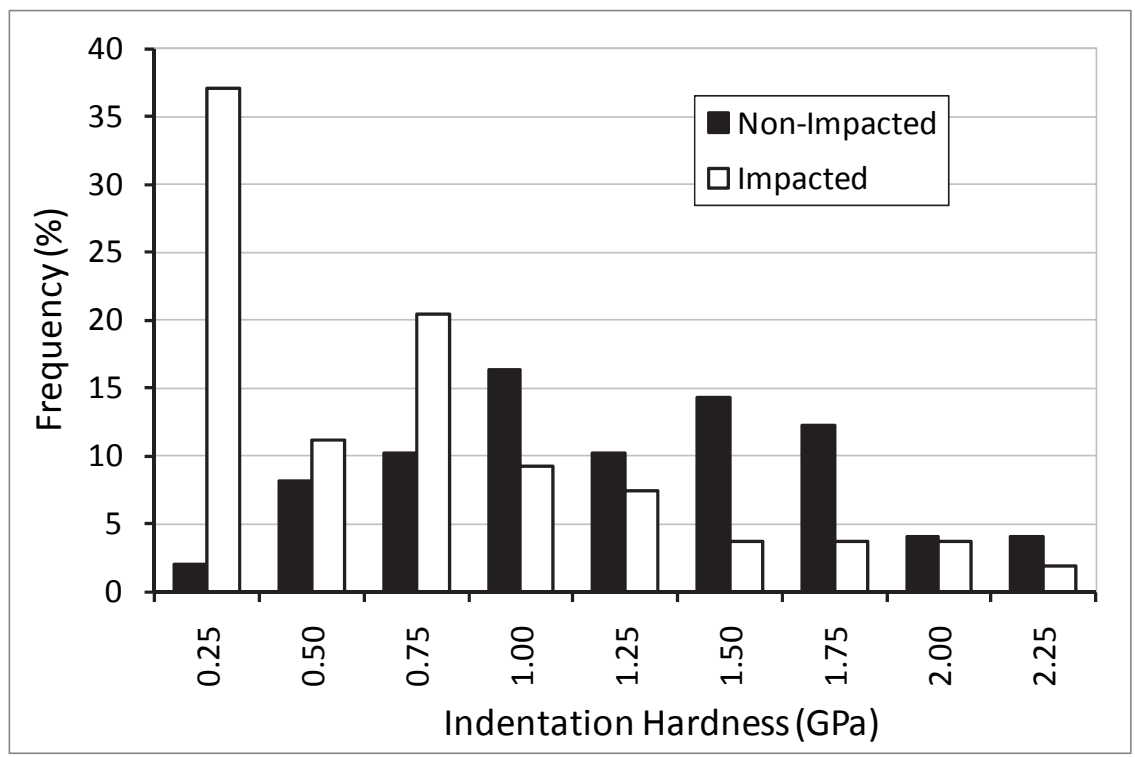

Figure 11. Hydrated phase fraction indentation hardness of impacted and non-impacted specimens.

These reductions in elastic modulus and, in particular, hardness in impacted samples suggest that the hydrate fraction of the cement paste, in addition to the overall microstructure of UHPCs, is degraded under high strain-rate impact loadings. The dehydration/vaporization mechanism proposed by DeJong and Ulm (2007) was shown as a possible deterioration mechanism resulting in decreased C-S-H packing factors and, in turn, reduced elastic modulus and hardness as measured by nanoindentation. However, unless additional secondary chemical bonding was to occur 
between C-S layers (similar to irreversible creep mechanisms (Mehta and Monteiro 2006) during the vaporization event), it is likely that rehydration of the hydrates would occur slowly. Furthermore, if such bonding were to occur, densifying the paste fraction and limiting rehydration, the elastic modulus and hardness would likely increase rather than decrease. Based on the results presented in Figures 7 and 8, it is clear that a majority of degradation in the UHPC indentation data set is associated with reductions in elastic modulus and hardness associated with inert particles and unhydrated cement. Therefore, it is likely that a majority of degradation in UHPCs following impact loading results from microfracturing and/or debonding. Recent research efforts determined similar damage mechanisms using petrographic analyses and X-ray diffraction, which have evidenced microfracturing and debonding as well as pressure- and temperatureinduced phase changes in siliceous aggregates and silica flour in the impacted region (Ren et al. 2011). 


\section{Conclusions}

A novel statistical nanoindentation technique was developed that spatially correlated the location of a large statistical indentation grid on an image obtained using BSE-SEM and chemical analyses using EDX. Using this method, the influence of high strain-rate impact loadings on the nanomechanical properties of UHPCs was determined. Significant degradation in both the elastic modulus and hardness occurred due to impact loadings of UHPCs. Closer examination of hydrated phases also showed degradation. However, a link between chemical changes in the hydrated phase fraction and deterioration in nanomechanical properties could not be made. Based on analyses of all indents performed on UHPC specimens, it is likely that much of the observed degradation in elastic modulus and hardness stems from microfracturing and debonding, which occurs due to the impact.

Future work involves additional experimental studies and quantitative data analyses to further evaluate the possible mechanisms of degradation present in UHPCs. New in-situ nanoindentation measurement techniques are also being investigated to improve the correlation between the desired phase being indented and its nanomechanical properties as well as elucidating the interaction between the indenter and the polished cement paste surface. 


\section{References}

Chen, J. J., L. Sorelli, M. Vandamme, F. J. Ulm, and G. Chanvillard. 2010. A coupled nanoindentation /SEM-EDS study on low water/cement ratio Portland cement paste: Evidence for C-S-H/Ca(OH)2 nanocomposites. Journal of American Ceramic Society (93) 1484-93.

Constantinides, G., and F. J. Ulm. 2007. The nanogranular nature of C-S-H. Journal of the Mechanics and Physics of Solids (55) 65-90.

Constantinides, G., and F. J. Ulm. 2004. The effect of two types of C-S-H on the elasticity of cement-based materials: Results from nanoindentation and micromechanical modeling. Cement and Concrete Research (34) 67-80.

Davydov, D., M. Jirasek, and L. Kopecky. 2011. Critical aspects of nanoindentation technique in application to hardened cement paste. Cement and Concrete Research (41) 20-29.

DeJong, M. J., and F. J. Ulm. 2007. The nanogranular behavior of C-S-H at elevated temperatures (up to $700{ }^{\circ} \mathrm{C}$ ). Cement and Concrete Research (37) 1-12.

Grady, D. 1996. Shock Equation of State Properties of Concrete. In Proceedings of Structures Under Shock and Impact IV. Southampton, UK: Computational Mechanics Publications.

Hughes, J. J., and P. Trtik. 2004. Micro-mechanical properties of cement paste measured by depth-sensing nanoindentation: A preliminary correlation of physical properties with phase type. Materials Characterization (53) 223-231.

Mehta, P. K., and P. J. M. Monteiro. 2006. Concrete: microstructure, properties, and materials. New York: The McGraw-Hill Companies, Ltd.

Millard, S. G., T. C. K. Molyneaux, S. J. Barnett, and X. Gao. 2010. Dynamic enhancement of blast-resistant ultra high performance fibre-reinforced concrete under flexural and shearl loading. International Journal of Impact Engineering (37) 405-413.

MIL-STD-662F. 1997. Military Standard: V50 Ballistic Test for Armor.

Oliver, W. C., and G. M. Pharr. 1992. An improved technique for determining hardness and elastic modulus using load and displacement sensing indentation experiments. Journal of Materials Research (7) 1564-83.

Ren, F., C. Mattus, J. Wang, and B. DiPaolo. 2011. Microstructural Characterization of UHPC Materials Subject to Impact Testing and Heating. Presented at the 2nd Annual Meeting on Advances in Cement-Based Materials, Nashville, TN.

Rushing, T. S., N. Boone, A. Irizzary, and R. Magee. 2009. Independent effects of matrix strength and fiber reinforcement on concrete's ballistic resistance. In Proceedings of the 8oth Shock and Vibration Symposium, San Diego, CA. 
Sorelli, L., G. Constantinides, F. J. Ulm, and F. Toutlemonde. 2008. The nanomechanical signature of ultra-high performance concrete by statistical nonindentation techniques. Cement and Concrete Research (38) 1447-56.

Trtik, P., B. Munch, and P. Lura. 2009. A critical examination of statistical nanoidentation on model materials and hardened cement pastes based on virtual experiments. Cement and Concrete Composites (31) 705-14.

Ulm, F. J., M. Vandamme, C. Bobko, J. A. Ortega, K. Tai, and C. Ortiz. 2007. Statistical indentation techniques for hydrated nanocomposites: Concrete, bone, and shale. Journal of American Ceramic Society (90) 2677-92.

Velez, V., S. Maximilien, D. Damidot, G. Fantozzi, and F. Sorrentino. 2001. Determination by nanoindentation of elastic modulus and hardness of pure constituents of Portland Cement Clinker. Cement and Concrete Research (31) $555-61$. 


\section{Appendix A: Backscattered Scanning Electron Micrographs}

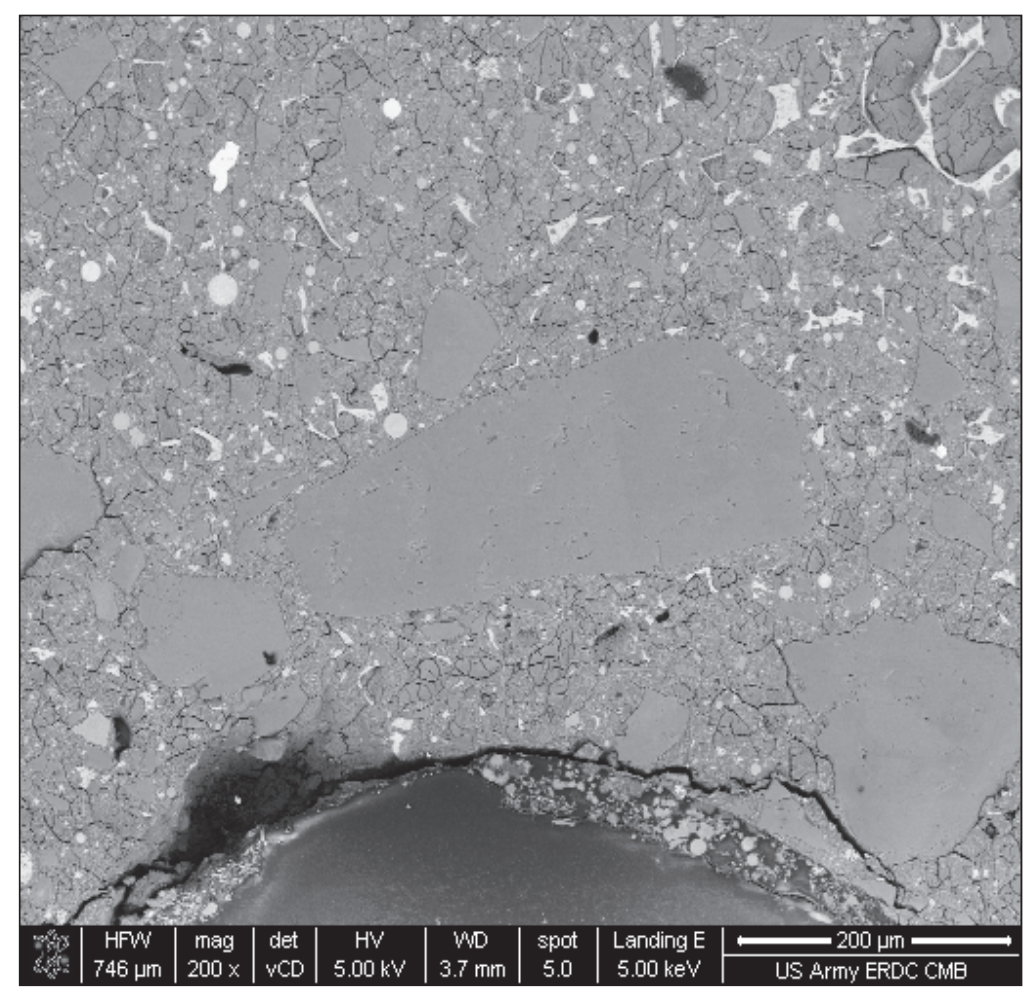

Figure A1. SEM micrograph of undamaged UHPC specimen. Bright grayscales correspond to unhydrated cement and silica fume, medium grayscales to hydration products, large inclusions are siliceous fine aggregates and silica flour, and darkest grayscales correspond to voids. Large entrained air void filled with epoxy shown at bottom of image. 


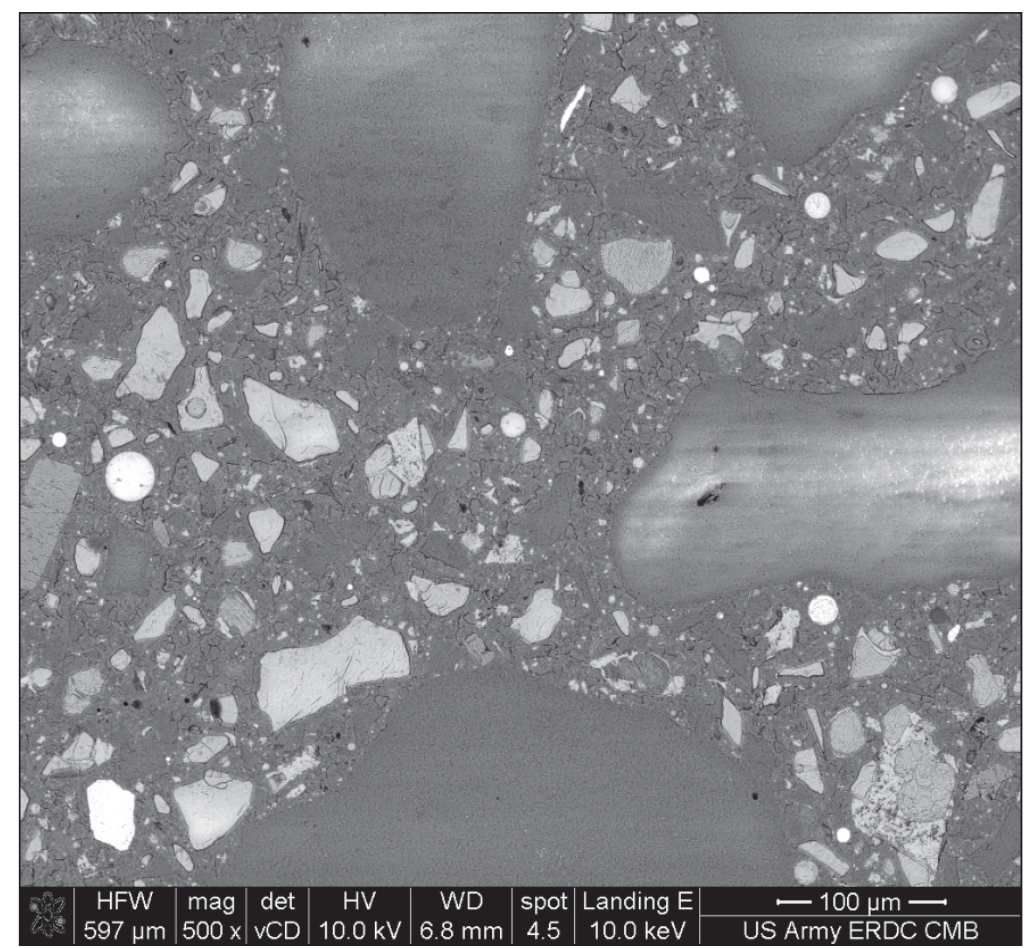

Figure A2. SEM micrograph of damaged UHPC specimen, including unhydrated cement, unreacted silica fume, fine aggregates, silica flour, and voids.

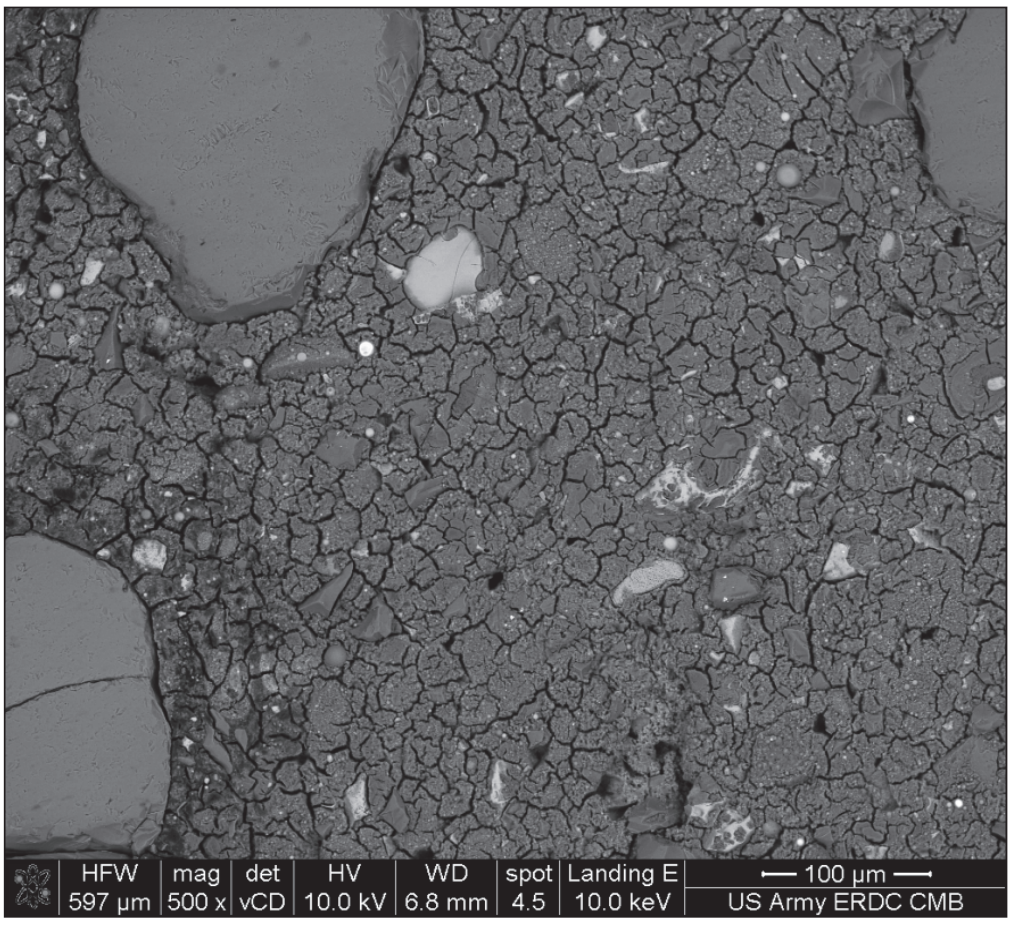

Figure A3. Challenges were encountered during sample preparation. Example here illustrates excessive shrinkage cracking of the UHPC surface caused by exposure to water during polishing which was allowed to evaporate from surface. The using of proper polishing lubricants (e.g., organic solvents) prevented these issues. 


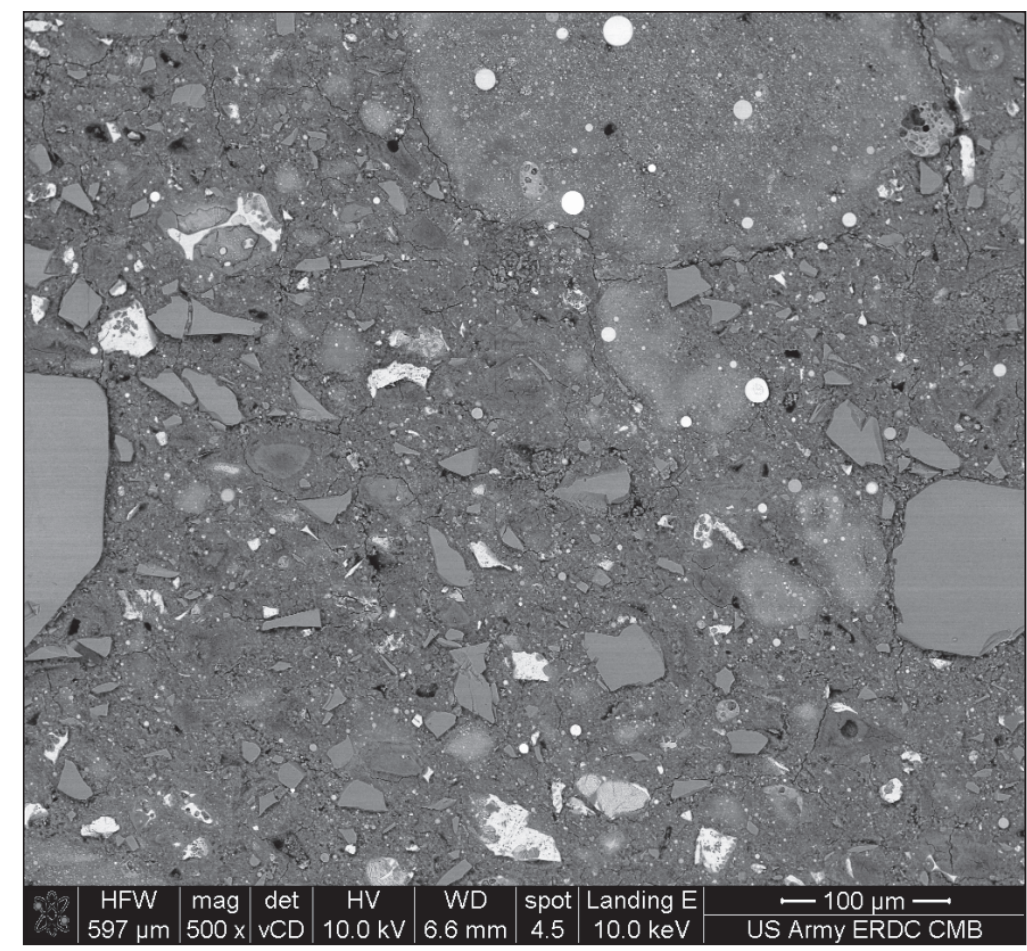

Figure A4. Example of well polished UHPC surface for nanoindentation testing and SEM/EDX analyses.

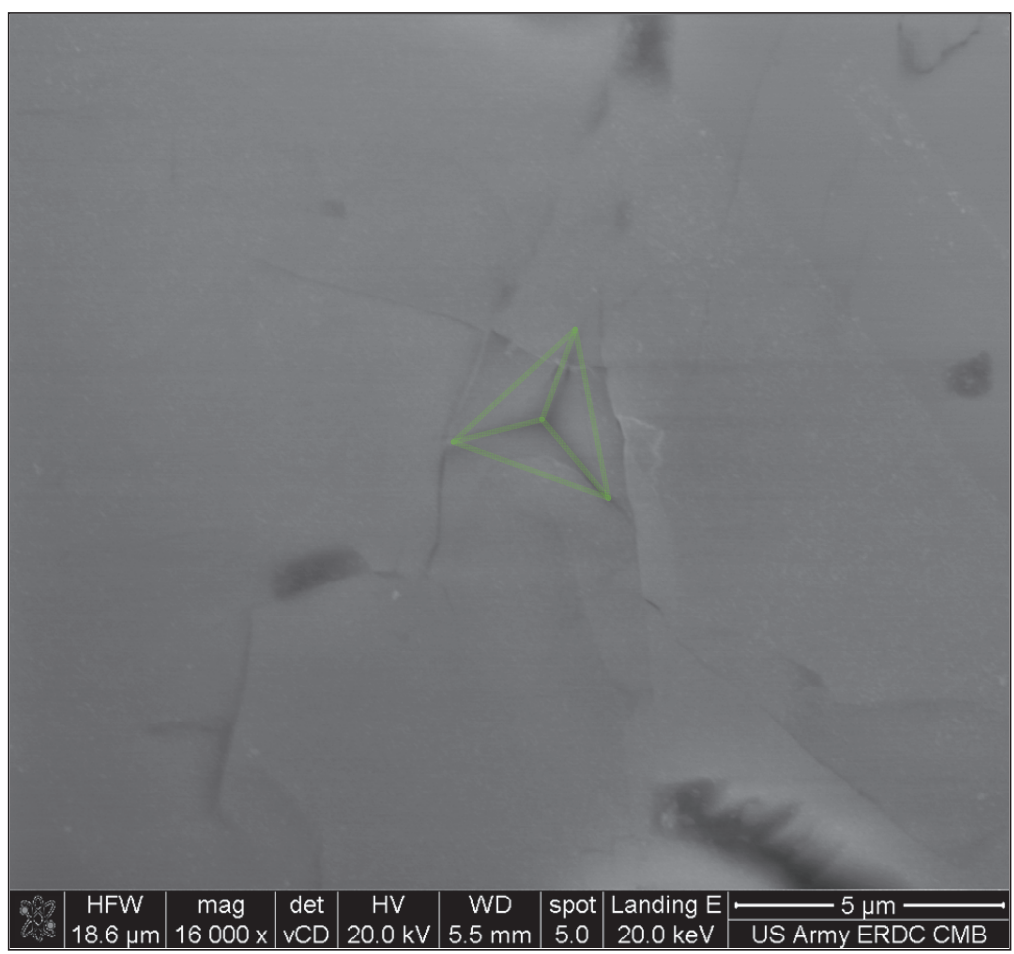

Figure A5. Typical $2 \mathrm{mN}$ indent on surface of siliceous fine aggregate. 


\section{Appendix B: Detailed Procedure for Spatially- Correlated Nanoindentation/SEM/EDX Analysis}

1. Polish samples according to procedures given by Buehler. Leave all samples in sample holder and either sonicate the entire sample holder or flush liberally with ethanol.

2. Use SEM to locate region where indentation can be performed (i.e., no extensive cracking, region of paste...).

3. Record a "map" of images to the location where indentation should begin, starting from an edge of the sample with some type of defect that can be easily identified using the optical microscope of the nanoindenter (e.g., a crack, weird aggregate shape). This could be done using a series of images or by using the "Stage Navigation" tool to create a montage of images ( $5 \times 5 \ldots 7 \times 7 \ldots$ ) of the entire region where the indentations will be performed.

4. Once the site has been located, vent the chamber and note the orientation of the sample in the SEM relative to the images that were taken. This will help in locating the intended site for indentation in the SEM. Looking at the monitor, the left side of images shown in the monitor corresponds to the side of the sample closest to the chamber door of the SEM. Typically, make a mark on the sample like that shown in Figure B1 when the chamber is vented. If this mark is placed closest to the tester in the nanoindenter sample holder when facing the indenter, it will ensure that the indents come out in approximately the same orientation as the initiation SEM images of the indentation site and will make it easier to line up the grid for EDX measurements.

5. Place the sample holder with correct orientation in the nanoindenter as shown in Figure B2. Using the original SEM image (map or montage), use the optical microscope to navigate to the indentation site after finding the location of an edge defect.

6. Once at the indentation site, place a grid of 2-mN indents according the transparency: with 50 indents in the $\mathrm{X}$-direction at a $10-\mu \mathrm{m}$ spacing and $10-\mu \mathrm{m}$ in the Y-direction at a spacing of $20-\mu \mathrm{m}$ - resulting in a grid of 500 indents, $490-\mu \mathrm{m}$ wide and $180-\mu \mathrm{m}$ tall. 


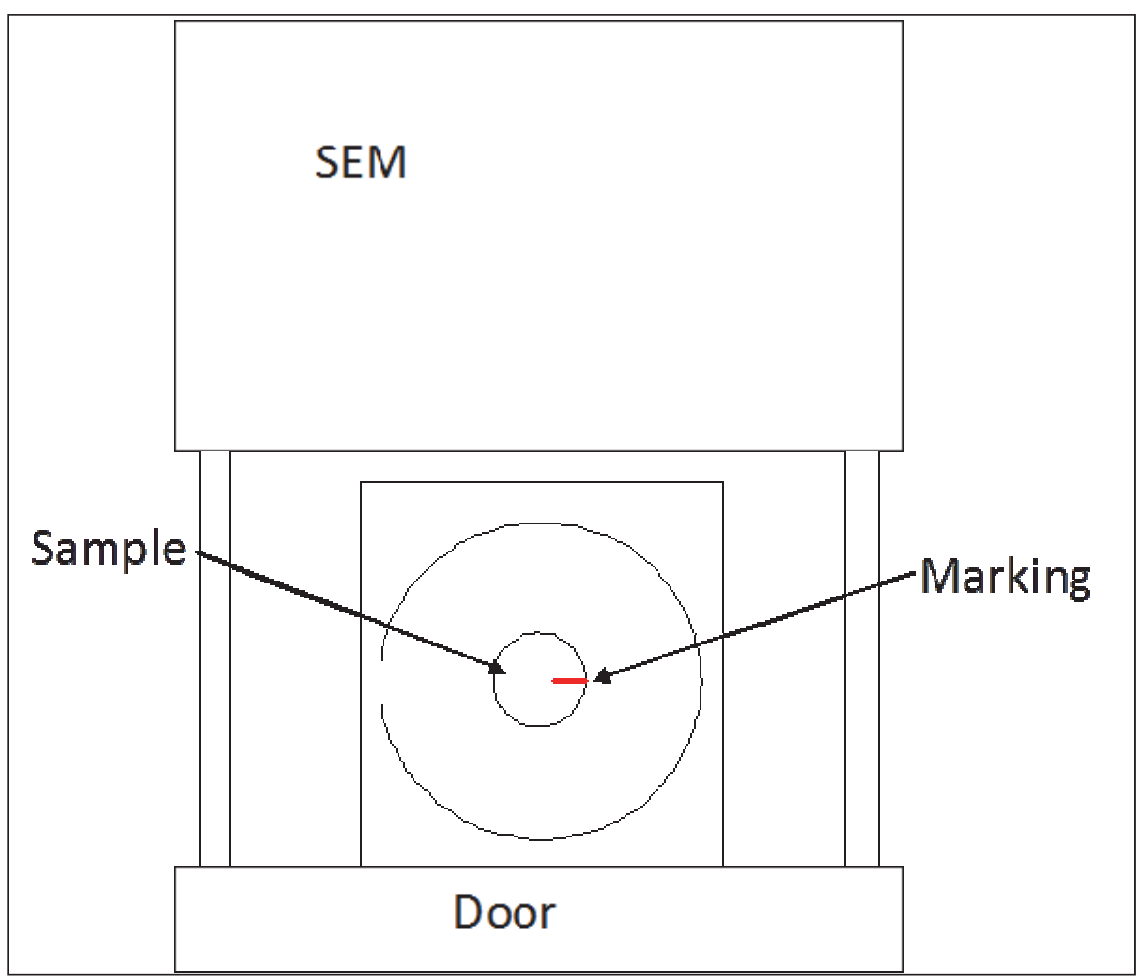

Figure B1. Plan view of SEM chamber showing proper alignment of specimen "marking" indicator to ensure that coordinate system of images obtained in SEM correspond to that of images observed in the nanoindenter and the statistical nanoindentation grid.

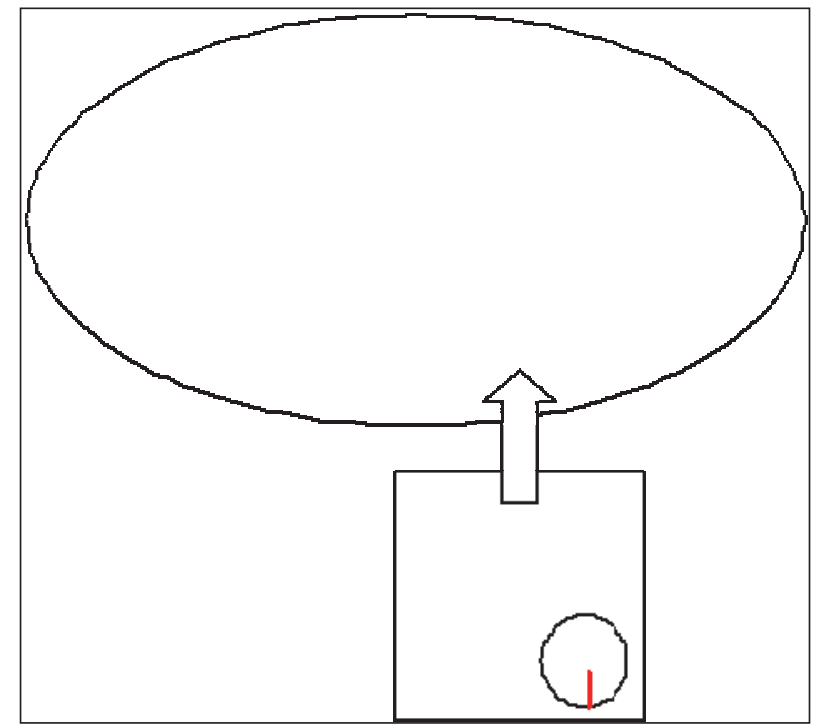

Figure B2. Proper alignment of specimen in holder for placement in nanoindenter to ensure coordinate system in SEM aligns with that of nanoindenter. 
7. Place a second set of marking "fiducial" $100-\mathrm{mN}$ indents, with three in the $\mathrm{X}$-direction at a spacing of $245-\mu \mathrm{m}$ and 10 indents in the Y-direction at a spacing of $20-\mu \mathrm{m}$. This will ensure that the start, middle, and end of each line of indents is clearly marked and visible in the SEM to help orient the transparency grid to perform the EDX line measurements.

8. Run the indentation program.

9. Place the sample in the SEM with the same orientation as that used originally to take images of the indentation site. Navigate to the indentation site using the original images.

10. Utilize ERDC-developed transparency (housed in SEM imaging room) to be placed on screen to aid in alignment. Transparency also provides the correct settings for magnification and working distance $(500 \mathrm{x}$ and $6.8 \mathrm{~mm}$, respectively). These settings are instrument dependent. Measurements typically have to be done in lo-vac mode to prevent drift on the sample and charging during imaging/EDX analysis.

11. Center the whole indentation grid on-screen (the 50x10 grid should fill up most of the screen). Also, make sure the location of the fiducial indents can be seen, as they'll be used to line up the transparency grid.

12. Using the EDX computer in object/linescan mode, change the image resolution to the highest setting, as described on the transparency and capture the image. Using the captured image in its maximized window, place the transparency on-screen with tape, lining it up with the $100-\mathrm{mN}$ set of indents.

13. Once the transparency is lined up, place the start and end of the linescan line at their correct positions according to the transparency. The user can magnify the image to full size (100 percent) to make sure that the start and end of the line are lined up well with the fiducial indents.

14. Set analysis software to perform chemical measurement on 50 points along the line - this should result in a distance between points of $\sim 10-\mu \mathrm{m}$. If it doesn't measure $10-\mu \mathrm{m}$, then the calibration is incorrect and needs to be redone.

15. Perform linescan. Typically, use "precise" scan settings.

16. Once the first linescan is finished, quantify desired elements ( $\mathrm{Si}, \mathrm{Ca}$, and $\mathrm{Al}$, or $\mathrm{O}$ if necessary).

17. Save the data into the project folder in the EDS analysis software - name the data in the project according to which line was being measured...1 to 50, 51 to 100, etc - the user will be prompted if saving individual point spectra is desired - do this else the data from each point on the linescan will not be obtained. 
18. Typically, only save two sets of linescan data per project file because the file sizes are excessively large.

19. Once the user is finished with the first linescan and has saved its data, move the line to the next level (51-100). Remember to reverse the line orientation, as shown by arrows on the transparency. This will ensure that the order of the EDX measurements corresponds to the order of the indents performed. It is good to check the alignment of the sample with the grid every couple of lines by recapturing the image and checking that the transparency is still in the correct location. This is typically not a problem in lo-vac mode but is still a good practice.

20. Repeat the procedure until the analysis of the entire indentation grid is completed.

21. To retrieve the data, open up the project and drop-down menu for the desired linescan and open up the point spectra. There will be a list of quantitative elemental analysis for each point. 


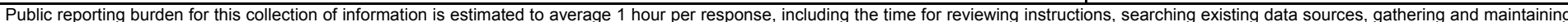

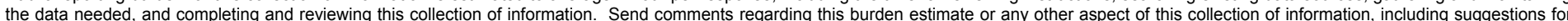

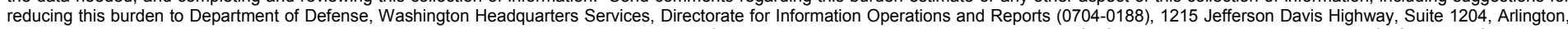

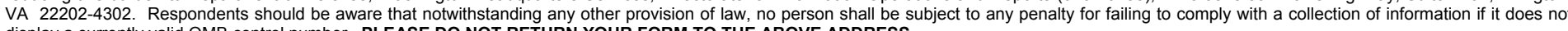
display a currently valid OMB control number. PLEASE DO NOT RETURN YOUR FORM TO THE ABOVE ADDRESS.
1. REPORT DATE (DD-MM-YYYY) 2. REPORT TYPE
3. DATES COVERED (From - To) April 2013

\section{TITLE AND SUBTITLE} Final report

Spatially-Resolved Characterization Techniques to Investigate Impact Damage in UltraHigh Performance Concretes 5a. CONTRACT NUMBER

5b. GRANT NUMBER

5c. PROGRAM ELEMENT NUMBER

\section{AUTHOR(S)}

Robert D. Moser, Paul G. Allison, and Mei Q. Chandler

5d. PROJECT NUMBER

149289

5e. TASK NUMBER

5f. WORK UNIT NUMBER

\section{PERFORMING ORGANIZATION NAME(S) AND ADDRESS(ES)}

8. PERFORMING ORGANIZATION REPORT

Geotechnical and Structures Laboratory

U.S. Army Engineer Research and Development Center NUMBER

3909 Halls Ferry Road

ERDC/GSL TR-13-17

Vicksburg, MS 39180

9. SPONSORING / MONITORING AGENCY NAME(S) AND ADDRESS(ES)

10. SPONSOR/MONITOR'S ACRONYM(S)

Headquarters, U.S. Army Corps of Engineers

Washington, DC 20314-1000

11. SPONSOR/MONITOR'S REPORT NUMBER(S)

\section{DISTRIBUTION / AVAILABILITY STATEMENT}

Approved for public release; distribution is unlimited.

\section{SUPPLEMENTARY NOTES}

\section{ABSTRACT}

Little work has been done to study the fundamental material behaviors and failure mechanisms of cement-based materials including Ordinary Portland Cement concrete (OPC) and Ultra-High Performance Concretes (UHPCs) under high-strain impact and penetration loads at lower length scales. These high-strain rate loadings have many possible effects on UHPCs at the microscale and nanoscale, including alterations in the hydration state and bonding present in phases such as Calcium Silicate Hydrate (C-S-H), in addition to fracture and debonding. In this work, the possible chemical and physical changes in UHPCs subjected to high strain-rate impact and penetration loads were investigated using a novel technique wherein nanoindentation measurements were spatially correlated with images using Scanning Electron Microscopy (SEM) and chemical composition using Energy Dispersive X-ray microanalysis (EDX). Results indicate that impact degrades both the elastic modulus and indentation hardness of UHPCs, and in particular hydrated phases, with damage likely occurring due to microfracturing and debonding.

\begin{tabular}{|c|c|c|c|c|c|}
\hline \multirow{3}{*}{\multicolumn{2}{|c|}{$\begin{array}{l}\text { 15. SUBJECT TERMS } \\
\text { Characterization } \\
\text { Concrete }\end{array}$}} & Damage & \multicolumn{3}{|c|}{ Nanoindentation } \\
\hline & & EDS & \multicolumn{3}{|c|}{ SEM } \\
\hline & & Impact & \multicolumn{3}{|c|}{ UHPC } \\
\hline \multicolumn{3}{|c|}{ 16. SECURITY CLASSIFICATION OF: } & $\begin{array}{l}\text { 17. LIMITATION } \\
\text { OF ABSTRACT }\end{array}$ & $\begin{array}{l}\text { 18. NUMBER } \\
\text { OF PAGES }\end{array}$ & $\begin{array}{l}\text { 19a. NAME OF RESPONSIBLE } \\
\text { PERSON: Robert D. Moser }\end{array}$ \\
\hline $\begin{array}{l}\text { a. REPORT } \\
\text { Unclassified }\end{array}$ & $\begin{array}{l}\text { b. ABSTRACT } \\
\text { Unclassified }\end{array}$ & $\begin{array}{l}\text { c. THIS PAGE } \\
\text { Unclassified }\end{array}$ & Unclassified & 33 & $\begin{array}{l}\text { 19b. TELEPHONE NUMBER (include } \\
\text { area code) } \\
601-634-3261\end{array}$ \\
\hline
\end{tabular}

